\title{
Spatial Microsimulation Modelling: a Review of Applications and Methodological Choices
}

\section{Cathal O'Donoghue}

Teagasc Rural Economy and Development Programme

Address Teagasc Mellows Campus, Athenry, County Galway, Ireland

Cathal.odonoghue@teagasc.ie

\section{Karyn Morrissey}

University of Liverpool

Address Liverpool, Merseyside L69 3BX, United Kingdom

Karyn.Morrissey@liverpool.ac.uk

\section{John Lennon}

Teagasc Rural Economy and Development Programme Address Teagasc Mellows Campus, Athenry, County Galway, Ireland john.lennon@teagasc.ie

ABSTRACT: Spatial microsimulation modelling has developed for over a half century and is now a mainstream analytical tool within the microsimulation community accounting for a very significant proportion of papers at conferences and within the journal. There have been a number of recent surveys of "mainstream" spatial microsimulation models and associated methodologies. The contribution of this paper relates mainly in extending these surveys by considering other micro based simulation models that incorporate a spatial or geographic dimension. We feel this is important as in many areas of microsimulation modelling, there are parallel literatures that have developed that apply simulation techniques to micro units that are not labelled microsimulation or in the case of the papers reviewed in this paper not labelled spatial microsimulation. The paper reviews a number of different application areas of spatially focused microsimulation models, including demography, welfare, health, regional development, transport planning, agrienvironmental analysis, crisis planning, land use and planning. We also review a number of the methodological choices made by modellers including scope, and spatial disaggregation, data sources, data creation methodology, validation and calibration and simulating change. 
KEYWORDS: Spatial Microsimulation, Survey, Methodology

JEL classification: C51 C55 C54 


\section{INTRODUCTION}

The idea to study and to project the socioeconomic and demographic development of a society and the operation of tax-benefit systems by simulating a large sample of individuals and their actions and interactions precedes the development of computers capable of running such simulations (Spielauer, 2011). The ability to create robust micro-level data offered a powerful alternative to the expense and time of assembling official microdata sets, such as published micro-level census records or individual/household survey data. This is especially true for models that wished to include spatial referencing. One might speculate that spatial microsimulation is too demanding or that microsimulation models are niche products or dubious black box models, applicable only with caution where other methods are not available. However, as the geographical impact of government policies, public and private investment and social networks becomes increasingly evident (Ballas and Clarke, 2009), researchers increasingly recognise that spatial microsimulation is an important research tool (Morrissey et al., 2014). Within this context, spatial simulation models with micro units of analysis have been increasingly applied to a range of policy areas, from demography, to transport planning, to health care.

Hägerstrand (1957) developed the first geographical application of microsimulation by employing micro-analytical techniques and an intervening opportunities model to study internal migration in central Sweden between 1946 and 1950. A decade later, Hägerstrand (1967) again employed micro-analytical techniques to study the spatial diffusion of innovation. Wilson and Pownall (1976) continued Hägerstrand's work by suggesting a new spatial modelling framework to represent the urban system based on the micro-level interdependence of household and individual characteristics. Further, they concentrated on the spatial distribution of a population and its activities and suggested that persons and their associated attributes should be defined separately in the form of lists, rather than represented in the form of matrices. In this manner, there is no loss of information and the storage is computationally efficient. In their representational framework, they were interested in estimating all the characteristics of the individuals that comprise the urban population.

Building on this work, Clarke et al., (1979) provided a representational and methodological framework for the formation of dynamic microsimulation models for interacting labour and housing systems. In particular, they considered the representation of household dynamics in an effort to design models for labour market and housing systems in the Yorkshire and Humberside regions in the early 1980s. They pointed out that the heterogeneous nature of households must be fully understood if the various processes governing their responses to change were to be 
modelled. Further work by Clarke et al., (1980) discussed the potential for the application of spatial microsimulation modelling to analyse socio-economic and public policies by addressing a series of important questions of practical and theoretical nature drawn from urban and regional planning. These examples included the analysis of transportation policies, housing expenditure and finance. In particular, Clarke et al., (1980) formulated a Monte Carlo based framework for transportation modelling at the micro-level. This framework stressed the importance of demographic, social and activity attributes of driver and passengers in determining whether individuals who have applied to a car-pooling scheme would in fact share a ride. Other early work in the field was the Harvard Urban Development Model, (Kain and Apgar, 1985) which aimed to simulate housing and neighbourhood improvement. Birkin and Clarke (1988) laid the groundwork for the suite of models developed at the University of Leeds (O'Donoghue et al., 2012).

As spatial microsimulation modelling has developed into a mainstream analytical tool within the social science community (Birkin and Clarke, 2012), there have been a number of surveys of spatial microsimulation models, including recent reviews by Ballas and Clarke, (2009), Tanton and Edwards (2013), Hermes and Poulsen (2012) and Tanton (2014). In particular, Tanton and Edwards (2013) in their edited book provide an in-depth review of the methodological approaches to what may be referred to as "mainstream" spatial microsimulation models; models that link micro level data containing more detailed individual level data, typically income data, to spatially representative constraints. However, over the years, parallel literatures have been developed that apply simulation techniques to micro units that are not labelled microsimulation or in the case of the papers reviewed in this not labelled spatial microsimulation. A classic example is the substantial poverty mapping literature developed at the World Bank, which are not always referenced in spatial microsimulation papers on inequality and poverty (Hentschel et al. 1998; Elbers et al., 2003).

Complementing the mainstream spatial microsimulation surveys, the contribution of this paper is the consideration of other micro based simulation models that incorporate a spatial or geographic dimension. We believe the contribution of this paper will allow for synergies between these mainstream and parallel literatures. In taking this broader perspective, we therefore do not go as deeply into the methodological angles considered very adequately in the surveys described above. Instead, this paper offers a survey of spatial microsimulation models, their development and application to date. Section 2 focuses on the variety of applications of spatial microsimulation models and describes their policy uses to date. In section 3 we review the methodological and 
data choices made by these models at a relatively high level. Finally, section 4 offers concluding comments on spatial microsimulation models and future usage.

\section{USES OF SPATIAL MICROSIMULATION MODELS}

To date spatial simulation models with micro units of analysis have been applied to a range of policy areas, from demography to transport planning to health care. The following sub-sections provide an overview of the range of applications to date.

\subsection{Demography}

Fundamental to almost all spatial microsimulation models is the creation of a micro-dataset containing the spatial distribution of demographic features. This field is a subset of a wider field of demographic microsimulation modelling and population projection (Van Imhoff, and Post, 1998; Van Imhoff and Keilman. 1991). The SVERIGE model dynamically simulates a number of demographic processes (Fertility, Education, Marriage, Divorce, Leaving Home, Migration, Mortality, Immigration and Emigration) in Sweden for use in a range of applications (Rephann, 2001). Lundevaller et al., (2007) using a similar methodology undertook a simulated population for a small area in Sweden. Birkin et al., (2009) describe a model, MOSES that again uses dynamic microsimulation of similar processes to underpin socio-economic analysis such as education and transport. Again using dynamic microsimulation, Ballas et al. (Ballas et al., 2005a) simulated the Irish population forward from 1991 to 1996 as benchmark comparison against the 1996 Census at a county level and projected the population forward into the future. In another paper, Ballas et al., using a different method known as GHOSTs, generated demographic projections of the UK population, which validated against the population census produced reasonably good estimates (Ballas et al., 2005b). The Australian models based at NATSEM use static ageing reweighting techniques to update the population (Phillips and Kelly, 2006) for use in a large range of analyses.

\subsection{Welfare, Poverty and Inequality}

A frequent and early use of spatial microsimulation and related techniques is as a data enhancement technique to allow policy analyses to be undertaken at a spatial level when spatial data is not available for this. A widespread example is the poverty mapping methodology largely developed at the World Bank. The methodology although not labelled spatial microsimulation uses identical methods for similar purposes as analyses within the spatial microsimulation literature (Hentschel et al. 1998; Elbers et al., 2003). The method involves parametric statistical matching of micro household data such as a budget survey to spatial census data to develop 
poverty maps. The method has been used to develop models for South Africa (Alderman et al., 2002), Malawi (Benson, 2005), Burkina Faso (Gräb and Grimm, 2008), Azerbaijan (Baschieri et al., 2005), Brazil (Elbers et al., 2008), Ecuador (Hentschel et al., 1999) amongst many others. The FAO (Davis, 2003) and IFPRI (Benson, 2006) have also used this method to explore food security related issues.

These methods have been utilised in parallel in developed countries to consider similar issues. For example NATSEM has developed a suite of spatial microsimulation models. Their modelling framework was initially built around a regional income model (Lloyd et al., 2000) and a model Marketinfo focusing on local expenditure and incomes focusing on market clients (King et al., 2002). There have been a number of models built in the UK for spatial poverty and inequality analysis. SimLeeds (Ballas and Clarke, 2001a) was developed to examine the labour market in and around the Leeds metropolitan area. Ballas (2004) used the SimLeeds framework to look at changes in poverty and inequality in Leeds and Sheffield between the 1991 and 2001 censuses. Tiglao (2002) extended this methodology to develop an income model for the Phillipines. Anderson (2007) has also developed a spatial microsimulation model for studying deprivation in England. Similarly, Morrissey and O'Donoghue, (2011) use a multi-stage method to simulate the spatial distribution of incomes in Ireland using the Simulation Model of the Irish Local Economy (SMILE).

Although developing spatial indicators of income inequality is in itself a useful tool to facilitate spatial planning, the addition of tax-benefit microsimulation modelling techniques allows for the spatial impact of policy in reducing poverty and inequality to be assessed. NATSEM's model SYNAGI (Synthetic Australian Geo-demographic Information), later called SpatialMSM, has been extended to simulate taxes and benefits (Chin et al., 2005) and has been developed to study issues related to differential spatial poverty and inequality rates (Harding et al., 2006). It has also been used to provide support for a social policy agency (King et al., 2002) and urban poverty (Tanton et al., 2009). Tanton (2009) also undertook a sensitivity analysis of aspects of spatial poverty. In Europe, the Leeds team extended their modelling framework to York and Wales (Ballas et al. 2005c) and later to cover the whole country, SimBritain (Ballas et al. 2005b )to look at the income and spatial distributional issues. The Irish model SMILE has also been linked to a static tax-benefit model to model net incomes and measure spatial redistribution (O'Donoghue et al., 2013a).

To date much of the literature in this area has focused on spatial income inequality (O'Donoghue et al., 2013a) with only a few papers taking advantage of the capacity of microsimulation models 
to simulate the impact of policy reform. Harding et al., (2009) simulated the impact of a national family tax benefit reform. The SimLeeds team used a partial tax-benefit model to simulate a number of tax and pension changes on income (See Ballas et al., 2003). SimBritain was also used to simulate the impact of changes to minimum wage, winter fuel payments, working families tax credits and new child and working credits (Ballas et al., 2007). The Irish SMILE model has also been used to assess the spatial impact of the economic downturn in Ireland (O'Donoghue et al., 2012).

\subsection{Health}

Health care service provision is a very important policy area, which involves both significant expenditure and given the often time bound requirements for interventions have major spatial issues related to access. A spatial microsimulation framework that contains micro units in the spatial location with health attributes and the spatial distribution of health services can therefore be a useful planning and analytical tool for health services. Morrissey et al. (2008; 2010; 2013) have utilised the Irish spatial microsimulation model SMILE to examine access issues related to the provision of GP and psychiatric services and the individual level determinates of acute hospital demand. This work involved detailed local modelling of health status and integrating spatial interaction models to assess access to health services. The onset of disability and ill health may increase the need for caring. Lymer et al., $(2008,2009)$ using a spatial microsimulation model for New South Wales in Australia modelled the regional incidence of disability and the potential requirement for care. In Leeds, the SimHealth model (Smith et al., 2007) linked the 2001 Census with the 2003 and 2004 Health Survey for England with the objective of simulating type 2 diabetes at a local level. Edwards and Clarke's (2009) SimObesity model also in Leeds tried to identify environmental factors that influenced childhood obesity noting particularly the relationship with poverty and social capital. Cataife (2014) also utilised this approach to model obesity in Rio de Janeiro.

\subsection{Other public policy}

With regard to education, Wu et al. (2008) in a dynamic demographic model of the Leeds area in the UK modelled the location and housing choices of university students. Rephann (2002) described an educational participation model of the SVERIGE incorporating the impact of spatial variables on participation. Kavroudakis et al., (2009) studying the hinterlands of 12 UK universities modelled areas of potential students and simulated the impact of changed rules on the eligibility for student loans, living costs and dropout rates and targeted admissions policies. 
Examining crime, Rephann and Öhman (1999) provide an overview of the issues related to modelling crime in a spatial microsimulation model, focusing on socio-economic correlations with crime and theorising about the possibility of endogenising crime within the model. With regard to crime based applications, the SimCrime model developed in Leeds (Kongmuang et al., 2006) was used to link crime data to spatial socio-economic data to look at the spatial incidence of crime victimisation.

The NATSEM models such as HOUSEMOD (Phillips and Kelly, 2006) have been utilised extensively to look at housing issues including housing stress which relates to a combination of low income and a high proportion of rent (Phillips et al., 2006), changes in commonwealth rent assistance and the need for rent assistance (Melhuish et al., 2004). The model incorporating both spatial population and housing weights can project demand for housing assistance to 2015. Analysis examples include the implications for social programs due to demographic and geographic change, the fiscal impact of changes in demand and the incidence of policy spatially. In the Netherlands, the LocSim model (Hooimeijer and Oskamp, 2000; Oskamp 1997) has been developed to model the impact of demographic change on the working of local housing markets, conditional on local housing policy strategies and together with a model of housing demand and migration to model the allocation of housing. Related to households, Clarke et al. (1997) used spatial microsimulation methods to model small area water demand.

\subsection{Regional development}

Given the fine level of spatial disaggregation provided by spatial microsimulation models, a significant amount of work has been done looking at the spatial impact of business location. In the Netherlands, Hooimeijer (1996), in a theoretical piece advocated the combination of eventhistory analysis, microsimulation and GIS to investigate how firms and individuals are linked through space. Van Wissen (2000) uses a firm based demographic model SIMFIRMS to model the lifecycle of firms in the Netherlands as an aid to spatial planning. Within the UK, Ballas and Clarke (2000) describe the early stages of their SimLeeds model focusing on travel to work flows and the impact of a new firm based upon a spatial interaction model, the spatial distribution of different types of workers in the Leeds area.

There have in particular been a number of examples in this firm-employee nexus of examining the economic impact of a firm closure. Rephann et al., (2005) for example used the Swedish SVERIGE model to look at the potential impact of the closure of the SAAB car plant, which given the recent decision of its parent company may be more than hypothetical soon. The 
analysis studies the re-employment rate, and the spatial impact on employment. The model was also used to simulate the hypothetical closure of a paper mill. Lindgren (1999) investigated the local labour market effects of a hypothetical closure of a paper mill, looking at indirect labour market effects. A number of papers in Swedish, summarized in Lindrgen et al., 2007, studied the local impact of building and operating a nuclear waste repository in a Swedish locality. Ballas et al. (2006) based upon a theoretical proposition (Ballas and Clarke, 2001b) in their SimLeeds spatial model using a journey to work model, were able to identify the location of workers of a major engineering plant closure and quantified their loss of income. As an additional step, they also modelled the resulting impact on expenditure and utilising a spatial interaction model simulated the impact on local retailers. They also quantified local inter-industry multipliers and long-term employment impacts of the change.

Examining retail store location and consumers demand and preferences, Birkin and Clarke (1985) developed a theoretical framework for using spatial microsimulation to look at retail dynamics. Nakaya et al. (2007) and Hanaoka and Clarke (2007) created a spatial microsimulation model for Japan, simulating expenditure at the household level and linking it to a spatial interaction model, based around lifestyle groups, looking at retail flows from individual households to individual retail units. The analysis was able to look at the spatial distribution of expenditure, average store turnover and customer profiles. Van Leeuwen et al. (2009) developed a model SIMtown to model spatial retail preferences in a number of Dutch towns. Generating a spatial microsimulation model of the population, they used a multinomial logistic model to estimate shopping behaviour. The microsimulation model was then used to look at the characteristics of shoppers and to simulate future developments such as the creation of a new retail store. A number of papers have modelled demand for tourism. Lundgren (2004) using the SVERIGE for domestic tourism in Sweden modelled the number of trips, type of trip and location of trips. Van Leeuwen and Nijkamp (2009) used spatial microsimulation techniques to generate a population of tourists in Amsterdam and considered their preferences for different types of tourist activity and service. Cullinan et al. (2008) used the Irish SMILE model to estimate demand for forest recreation.

\subsection{Transport planning}

A parallel area of spatial microsimulation is in the area of transport planning (Hollander and Liu, 2008). This literature focusses on modelling travel over transport networks, mode of transport, car ownership, congestion and transport control measures. While much of the literature focuses on transport planning and civil engineering issues, we cite some of the key works in the literature due to their relevance in modelling social science transportation issues and because of their 
relevance for the extensive land-use and transportation literature described in the next section. See Miller and Salvini (2001) for a summary. A special issue of Networks and Spatial Economics, on transport microsimulation, edited by Nagel and Wagner, (2002) gives an overview of some of the issues of current relevance to transport microsimulation. A useful tool for transport modelling, CEMDAP, is described in Bhat et al. (2004).

Fundamental to travel microsimulation is the modelling of activity and an appreciation of the dynamic nature of this activity/travel (Miller, 2009). Bradley and Bowman (2006) summarise the components of Activity-Based Microsimulation Models (AMOS). Ryuichi's AMOS model, prototyped in Washington DC, is an example of an activity based model of transportation (RDC, 1995; Kitamura et. al., 1993, 1995; and Pendyala et. al., 1995). This model predicts changes in travel behaviour following changes in the travel environment. The model is a tour based model rather than a trip based model in that it models joined up sets of journeys rather than simply single independent trips. It contains five components: (a) a Baseline Analyzer to ensure baseline diary is complete, (b) a Response Option Generator which models the preferred behavioural response to a change in the travel environment, (c) an Activity-Travel Planner Pattern Modifier which models the simulate possible changed travel patterns, (d) an Evaluation Routine that assesses the impact of the change as a function of time based utility and (e) an Acceptance Routine is the decision routine that determines the optimal travel decision. It is thus similar methodologically to other behavioural analyses used in microsimulation modelling such as the labour supply choice (Van Soest, 1995).

However, while the microsimulation approach is very detailed and can avoid aggregation bias (Sivakumar, 2007), De Palma and Marchal (2002) argue that very detailed dynamic microsimulation models of transport "often requires large computing resources as well as expensive and time-consuming calibration procedures and is, therefore, only practical for small networks". Raney et al. (2003) however describe how their TRANSIMS model can be used to simulate travel across an entire country, Switzerland using parallel computation, linking a population dataset, combined with daily travel plans, modal and route choice and then the traffic microsimulation to model congestion and feedback to make travel choices consistent with congestion and vice versa.

The AMOS model calibrates travel diaries based upon a collected travel behaviour survey, referring to what Miller (2009) refers to as a "behaviour first" approach; undertaking rigorous behavioural statistical analysis first, before undertaking a simulation. In many respects therefore activity focused travel microsimulation has much in common with social science studies of time use (for a simple example in the spatial microsimulation literature, see Anderson et al., 2007). 
Another example of a survey based behavioural simulation is Nielsen, (2002) which describes a state preference survey combined with a mesoscopic method (groups of agents rather than individual agents) for use in route choices in Copenhagen where alternatives were possible. Doherty and Miller (2000) describe a novel methodology for collecting household scheduling data.

Within the field of transport microsimulation modelling there is a further choice in the level of complexity, modelling daily activity schedules as per for example the TRANSIM model (Raney et al., 2003) or the modelling of real time individual movements such as land change etc as in the case of Laird et al., (1999). The latter's level of detail allows for an evaluation of the implementation of road management planning for example. The DRACULA model (Liu, 2005) attempts to combine the two by calibrating microscopic individual traffic movements to daily activity schedules by modelling sets of pre-specified journeys from origin to destination rather than a junction by junction travel flow model, thus as Liu argues reducing the computation cost of the process and also possibly improving the plausability.

A clear economic analysis using transport microsimulation modelling is the potential impact of instruments such as congestion charging or road pricing systems. Pendyala et al. (1997) utilised the AMOS model to simulate the impact of road pricing in Washington DC. Besides the land use implications and the economic instrument design issues, an obvious potential linkage with the social science focused spatial microsimulation literature is to quantify the distributional impact of congestion pricing. Santos and Rojey, (2004) undertook a partial microsimulation approach to this issue across towns in the UK, however linkage to a larger scale microsimulation model would have allowed for more in depth distributional analysis. Eliasson and Mattsson (2006), applying a transport model to a specific travel survey in Stockholm, were able to do this, however it has a relatively limited spatial representation. Another area of interest in regional science relates to environmental issues related to travel, commuting and transporting goods (Hooimeijer, 1996).

\subsection{Agriculture, marine and environment}

The interaction between human activity and the environment is strongly influenced by spatial location. The use of spatial microsimulation models can be useful for modelling socio-economicenvironmental interactions and policies. Svoray and Benenson (2009), in a special issue of the journal Ecological Complexity focusing on environmental microsimulation models, highlight the increasing use of microsimulation models within the environmental field, emphasising the availability of spatial environmental data and models in relation to the interaction between 
ecological and socio-economic systems. Kruseman et al. (2008a, 2008b) developed the MAMBO model of livestock and agriculture in the Netherlands to model the impact of tightening environmental policy on Phosphate emissions. Peters et al. (2002) model scenarios relating to wastewater technology in relation to human waste within a Swiss region. Potter et al., (2009) developed an environmental focused model, linking scientific data with farm management data and it was used to model carbon sequestration from cropland in the USA.

With regard to agriculture, Hynes et al. (2009b) developed a model of spatial farm incomes as part of the SMILE, which has been used to examine the impact of EU Common Agricultural Policy Changes (Hennessy et al., 2007). Using this income distribution and a coarser spatial scale, O'Donoghue et al. (2013a) extend the farm focused models to include wider household income sources to be able to assess the wider economic sustainability of farm households. Clancy et al. (2013) utilised SMILE in Ireland to assess the optimal spatial location for the growth of willow and miscanthus for biomass production. Lindgren and Elmquist (2005) linked natural sciences and economics in their Systems AnaLysis for Sustainable Agricultural production (SALSA) model to evaluate the economic and environmental impact of alternative farm management practices on a site specific arable farm in Sweden.

A variant of the agri-SMILE (Hynes et al., 2009b) focuses on recreational activity in forests within a single city (Cullinan et al., 2008). Also with a small area focus (a number of municipalities), van Leeuwen et al. (2008) have developed a model exploring the linkages between on and off-farm employment, which is becoming an increasing part of farmer's incomes in the EU. While there have been many examples of aspatial static microsimulation models that have simulated greenhouse gas emissions, the spatial models that have modelled these emissions tend to be those where spatial context is relevant such as agricultural models (Hynes et al., 2009a), land use (Moeckel et al., 2007) or transportation issues (Mavoa, 2007). In terms of biodiversity related issues, microsimulation models were used to look at a range of issues including wildlife-recreation interaction (Bennett et al., 2009) and the non market value of wild bird conservation (Hynes et al., 2010), and participation in Rural Environmental Protection Schemes, (Hynes et al., 2008). Whilst, the updated SMILE model for 2011 developed by Farrell et al., (2013) was extended to include a marine component (Morrissey et al., 2013). Using spatial microsimulation Morrissey et al., (2013) linked marine sector level economic parameters on income and employment, to commuting data for Ireland (POWCAR) and individual level income (EU-SILC). The SMILE marine component is the first attempt in Ireland to link industrial sector data with individual level data. 


\subsection{Crisis planning and management}

One of the advantages of microsimulation models is their capacity for use as an experimental platform for examining the impact of rare or extreme events (Hoshen et al., 2007). Some analyses have been undertaken in a relatively aspaital context such as Grist (1979). For example Brouwers (2005) and Brouwers et al., (2004) utilised the SVERIGE model (Holm et al., (2002) to simulate the transmission of a Smallpox virus in Sweden. Brouwers (2005) looked at the incidence of the infections per type of location over a time horizon. The framework could potentially have been used to examine the economic cost of such an outbreak for assistance in crisis management planning and insurance design. Chen et al., (2006) modelled Hurricane evacuation procedures in a local area in Florida. Hoshen et al. (2007) developed a grid based spatial microsimulation model for the UK and Ireland to look at disease transmission. Each individual was assigned day and night locations (home, school, work), personal schedules (starting and ending work), age, sex and disease status (susceptible, infected, latent (non-infectious), infectious and immune). The lengths of the latent and immune stages can also be varied subject to disease type as well as infection and clearance rates.

\subsection{Land use and spatial planning}

While most of the previous papers have treated their environment as exogenous, there is a large overlapping field of land use modelling incorporating a range of techniques including microsimulation modelling and spatial interaction models that treat the environment as endogenous. As a major alternative literature, this section highlights the main characteristics of these models.

The field largely focuses on alternative land-uses and locational choice. These, largely urban landuse focused models largely originated out of civil engineering and planning research rather than the social science originating models described above. There have been a number of large scale integrated modelling efforts to link transport microsimulations with land use including the California Urban Futures (CUF) Model (Landis and Zhang, 1998a, 1998b), the Integrated Land Use, Transport and Environment (ILUTE) model in Canada (Miller et al., 2004), the Urban Simulation (UrbanSim) model in Seattle (Waddell, 2000a, 2000b, 2002; Alberti and Waddell 2000, Waddell, P. and Ulfarsson, G.F., 2004; Waddell, P. and Borning, A., 2004) and the models of the Transport and Land Use Model Integration Program (TLUMIP) in Oregon (described in Wegener, 2004). 
Wegener and Spiekermann (1996) explored the potential of spatial microsimulation for urban models, focusing on land-use and travel models. They argued that a new generation of travel models had emerged, which required more detailed information on household demographics and employment characteristics at the small area level. They also pointed to new neighbourhood-scale transport policies aimed at promoting public transport, walking and cycling and the need for environmentally sustainable land use policies with regard to transportation. These policies required detailed information on the precise location of the population and its activities. Wegener and Spiekermann (1996) also point to the need for urban models to forecast the environmental impacts as well as the economic impacts of land-use transport policies. They provide a microanalytic theory of urban change and demonstrate how such a model of urban change can function through microsimulation. Related to this work, the ILUMASS modelling system in Dortmund, Germany (Strauch et al. 2005) has been constructed with the aim to incorporate "changes of land use, the resulting changes in activity behaviour and in transport demand, and the impacts of transport and land use on the environment".

Miller et al. (2004) describe an example of this type of model, the ILUTE (Integrated Land Use, Transportation, Environment) modelling system whose aim is to "simulate the evolution of an entire urban region over an extended period of time" using a microsimulation approach of urban land use and transportation. The model links travel choice, car ownership and mode together with locational choice, a set of businesses and households with trade and monetary flows consistent with an input output matrix. Land development is modelled on both a grid basis and a building basis. It operates in parallel to an activity based transport model, Travel/Activity Scheduler for Household Agents, (TASHA).

The UrbanSim modelling framework has been developed for application in different locations with substantial documentation (Waddell, 2002). Felsenstein et al. (2007) have utilised the framework for Tel Aviv, simulating the impact on land use of changes such as the alternative location of shopping malls while Franklin (2005) developed the framework for use in a congestion charge analysis in Stockholm. Joshi et al. (2006) used the framework to simulate the impact of light rail on urban growth in Phoenix, while Zhao and Chun (2006) evaluated the framework in forecasting land use change in Florida. Nguyen-Luong and Moran (2008) used UrbanSim for developing a model SIMAURIF in Paris.

Another application of spatial microsimulation methods in the Netherlands is the regional planning model, RAMBLAS, which is based on simulating daily activity patterns in the Eindhoven region (Veldhuisen et al., 2000a, 2000b, 2005). The spatial units involved are 
municipalities (33), zones (400) and postal areas. For each municipality, households are derived from the population according to age, gender, marital status and distributed over the dwelling stock. From this, a list of individuals in each municipality is created, characterised by age, gender and marital status and also by the zone/postal area where they live, go to school or work at. The main aim of RAMBLAS is to estimate the intended and unintended consequences of planning decisions related to land use, building programs and road constructions for households and firms (Veldhuisen et al., 2000a, 2000b). Finally, while most of the land use models do not incorporate structural land markets where prices are derived from supply and demand, Zhou and Kockelman, (2010) using a spatial microsimulation land model attempt to model property transactions at the level of the parcel.

\section{MODEL COMPONENTS: DATA, PROCESSES AND POLICY INSTRUMENTS}

In this section we consider some of the modelling choices faced by spatial microsimulation models. As a survey article, we have been selective in terms of the headings considered, focusing on relatively high level fundamental choices rather than very specific modelling choices. For an overview at a more detailed level, the reader is referred to Tanton and Edwards (2013) and Tanton (2014) in this issue. Focusing on papers within the social science spatial microsimulation modelling literature, the following issues are discussed in turn;

- Scope, and spatial disaggregation

- Data Sources

○ Data Creation Methodology

- Validation and Calibration

○ Simulating Change

\subsection{Scope and spatial disaggregation}

One of the first decisions in building a spatial microsimulation model is the spatial dimension of the model. These dimensions can be divided into the spatial scope and spatial disaggregation of the model. With regard to spatial scope, this may vary from a village (Kuiper and Ruben, 2006) or farm (Lindgren and Elmquist, 2005) to a city (Ballas and Clarke, 2001a) to a country (Harding et al., 2006) to a continent as in the case of the EU comparative tax-benefit microsimulation model EUROMOD (Immervoll et al., 1999). The relevant scope will depend upon the user and use of the model and may be constrained by the complexity associated with the methodology. Spatial disaggregation refers to the nature of the spatial levels within the model. This can vary in 
decreasing size from country in EUROMOD to a region in an inter-regional analysis (Lloyd et al., 2000), to spatial districts (Ballas and Clarke, 2001a; Chin et al., 2005) to spatial coordinates (Cullinan et al., 2011). The greater degree of spatial disaggregation, the greater the degree of interarea analysis that may be conducted (Baulch and Minot, 2006).

To date, the literature indicates a divide between the spatial scope of models across different countries. Those coming from a social policy origin such as Harding et al. (2009) and Tanton et al., (2011) in Australia and O'Donoghue et al., (2013a) in Ireland have a national scope, reflecting their (primarily) national government stakeholders. In contrast, the University of Leeds based group have focused on city based models, reflecting the history of planning and the local government stakeholders. In general the spatial disaggregation has tended to be district or zone level. In terms of planning purposes, there is little added value and very little data availability for going to a building level analysis. A similar divide in spatial scope exists with regard to policy applications. Models of the retail, transport and regional development tend to utilise a city focus. However, in contrast, some agri-environmental based models utilise a national level unit of analysis (Hynes, et al., 2009a; 2009b). Indeed, research has indicated that the choice of spatial resolution or level of disaggregation can be important. Benenson (2007) showed that when using a finer resolution than the "true" resolution in environmental analysis, one can result in different conclusions. For example where the impact of pollutants is non-linearly related to concentration, particularly spatial concentration, then a smaller resolution may understate the significance. Sometimes the scope and resolution is very small when one is interested in site specific phenomena such as the model of walking trails on biodiversity in parkland (Bennett et al., 2009). Finally, whilst a division has been observed, it is important to note that it may exist because the desired spatial disaggregation is not available within the data. For example Felsenstein et al. (2007) in using Urbansim to create a grid based model for Tel Aviv only had zonal data and assumed a uniform distribution across the zone to populate grids. While this may approximate reality in an urban area, it is not the case in rural analyses as identified in Cullinan et al., (2008).

\subsection{Data sources}

The ideal base dataset for a spatial microsimulation model is one collected specifically for modelling purposes with the appropriate scope and level of spatial disaggregation. While it is rare for datasets to be created specifically for modelling purposes, datasets collected for other administrative or scientific purposes are usually used to develop models. An example is the use of a $100 \%$ sample of micro data geo-referenced to small areas used in the SVERIGE model, (Vencatasawmy et al., 1999; Holm et al., 1996). The ASTRID database used by the model includes 
detailed information of Swedish individuals, companies and properties for the period 1985-2003, spatially defined to $100 \mathrm{~m} 2$ and census data every five years from 1960 until 1990. Statistics Sweden (SCB) collects this data and SMC has been entitled to use those data for research purposes. An example of another full scope environmental spatial dataset used for spatial microsimulation is the National Resources Inventory used by Potter et al. (2009). However in most cases a single dataset is usually not available. For example while income surveys that are typically used in static microsimulation models have good income and socio-economic information at a micro level, sufficient for policy analysis, their spatial disaggregation is limited, often to high level regional information. On the other hand while Census data is typically comprehensive in terms of spatial scope, the quality of in particular income data, where it is available, is often not of sufficient quality or disaggregation for policy analysis. Many models therefore typically require the linkage of datasets of different types using statistical techniques. The most common data requirement for spatial microsimulation models is the availability of small area census data, available in most countries internationally. UK model's (Ballas and Clarke, 2001a; Anderson et al. 2007) uses the UK Census Small Area Statistics (SAS). The Australian SpatialMSM model uses the Australian population census. The Irish SMILE household model uses Census small area population statistics (Morrissey et al., 2008). Pritchard and Miller (2008) use Census Metropolitan Area (CMA) for Canada. While these models mainly use tabulated small area data, many of the poverty mapping models use geo-referenced census micro data (Hentschel et al. 1998; Elbers et al., 2003).

Associated micro data can either be simulated from small area tabulations as in the case of Pritchard and Miller (2008) or linked with another geo-referenced dataset such as an income or expenditure survey. The SimLeeds model links the Census Sample of Anonymised Records (Ballas and Clarke, 2001a), Anderson et al. (2007) link panel data from the British Household Panel Survey (BHPS) to Census data, the Australian model links various micro data sets such as the Australian Bureau of Statistics Survey of Income and Housing (SIH) (Tanton et al., 2011), while the Irish model SMILE, links to European datasets, the Living in Ireland survey (LII) (Morrissey et al., 2008; 2010; 2013) or the EU-SILC (O'Donoghue et al. 2013a). Specialised datasets are also matched for particular data enhancement purposes such as the British Crime Survey (BCS) for the SimCrime model (Kongmuang et al., 2006) and the Health Survey for England for the SimObesity model (Edwards and Clarke, 2009). Within Europe, agricultural focused models have typically linked farm census data either at the macro level (Hynes et al., 2009b) or the micro level (Pesti and Kaposzta, 2008) with micro farm survey datasets such as those based upon the EU Farm Accountancy Data Network. 


\subsection{Data Creation Methodology}

Where a single spatial dataset does not exist, the generation of a base dataset for the spatial microsimulation model will involve a data fusion or imputation techniques. Given the general lack of data availability, this is often the most challenging task. Hermes and Poulsen (2012) review the main options for spatial data generation and classify the methods into synthetic reconstruction and reweighting methods. Synthetic reconstruction involves the generation of a new dataset with spatial attributes, while reweighting takes an existing dataset and applies alternative weights. The most straightforward of the resampling methods is statistical matching. Resampling methods are possible when one has spatial micro data and involves directly linking one dataset to another, such as a geo-referenced small area census to an income micro survey. Decoster et al. (2009) reviews four alternative methods, parametric and non-parametric regressions, grade correspondence matching and minimum distance matching. All four methods involve identifying overlapping variables between the two datasets. The regression based methods estimate sets of equations relating the variables to be matched (i.e. non overlapping) to the overlapping variables on the imputation dataset and then simulate the values in the master spatial dataset. The grade correspondence method, sometimes within sub-group, ranks the matching variable or variables and transfers the micro-units on the basis of rank. Lastly the minimum distance method identifies units in the master dataset that look most similar to the imputation dataset and transfers them. This is the methodology utilised by the World Bank type poverty mapping exercises (Hentschel et al. 1998).

However as the availability of spatial micro data is limited, other methods are typically required. One of the earliest methods, Iterative Proportional Fitting (IPF) (Deming and Stephen, 1940) is a mathematical method for generating a joint distribution from a set of marginal distributions (Norman, 1999; Huang and Williamson, 2001). It allows us to convert a set of small area census tables given a subset of dimensions into a single joint table. Households are then synthetically generated using Monte Carlo methods. Birkin and Clarke (1988) used IPF to create the SYNTHESIS model. Whilst Williamson $(1992,1996)$ used IPF to examine community care policies for the elderly. More recent work by Simpson and Tranmer (2005) linked IPF with small area statistics generated by parametric multilevel matching techniques to generate a representative population. Pritchard and Miller (2008) discuss the properties and generalisations of the IPF method in more detail.

The current literature on spatial microsimulation has focused on reweighting methods. Hermes and Poulsen (2012) discuss and critique a number of these methods including; 
○ Deterministic reweighting using IPF

○ Deterministic reweighting using weights from GREGWT

- Combinatorial Optimisation

The deterministic approach to reweighting national sample survey data is an attempt to fit small area statistics tables or benchmarks for each small area without the use of random sampling procedures (Ballas et al., 2005a). IPF may be used to generate cross-tabulated control totals at the small area. These are compared with similar cross-tabulated totals from the survey data to produce weights. The method typically produces weights where the control totals and the survey data have the same unit of analysis. This allows any number of changes to the data in the model to be made until an optimal reweighting methodology is reached (Smith et al., 2007; 2009).

In creating simBriain, Ballas et al. (2005a) note that when they compared the weighted data with their Census counterparts, there were, in some cases, comparatively high over and underestimates of some variables that were not used as constraint variables. In order to reduce this error further and produce a better fit, a swapping algorithm was developed to swap suitable simulated units between small areas. A further issue was that the survey selection pool contained less than a thousand individuals and was being used to estimate area populations, which contain thousands of individuals. This produced weights which were very small, less than 1 , as the initial reweighting process was repeated a number of times for convergence purposes. In order to alleviate this situation, Smith et al., (2009) apply a scaling factor on the weights to adjust them back to numbers, which equate more to actual population values. Further applications include the estimation of the incidence of income poverty for each district in Wales (Anderson, 2007) and the estimation of obesogenic variables in the city of Leeds (Edwards and Clarke, 2009).

An alternative mechanism for generating weights for spatial micro data is to use a regression based reweighting method. An example is GREGWT, which is a generalised regression reweighting algorithm written by the Australian Bureau of Statistics (ABS) which was developed to reweight their survey data to constraints from other Australian data sources (see Tanton et al., 2011). GREGWT is a constrained distance minimisation function which uses a generalised regression technique (Bell, 2000) to get an initial weight and iterates the regression until an optimal set of household or individual weights for each small area is derived. GREGWT is also deterministic, in that it generates the same result each time it is run. Optimisation is achieved when the difference between the estimated count and the known census count for each of the constraint variables is minimised or a predefined number of iterations is made at which stage the iteration stops. The iterative calculations are carried out for each small area one at a time. Once 
the reweighting process is finished, each household in the survey dataset should have a weight for each census small area that had counts for the constraint variables used. The method is effective for most districts in Australia, but areas with low population pose some problems for the method.

The final approach to generating spatially disaggregated microdata is the use of combinatorial optimisation methods which can be used to reweight an existing microdata sample to fit small area population statistics. For example, aspatial microdata sets can be reweighted to estimate the micro population at a local spatial scale (Ballas and Clarke, 2000). The method differs from IPF primarily in that it reweights or samples from a micro dataset until a new micro-dataset is generated that reflects the characteristics of the small area. Simulated annealing was originally applied in thermodynamics in the 1950s, when Metropolis et al. (1953) developed a procedure for simulating the progression of a solid material to thermal equilibrium. Since then, simulated annealing has been employed as an optimisation technique to solve various combinatorial optimisation problems (Van Laarhoven and Aarts, 1987). In a geographical context, this method has been applied to solve examine a number of policy areas, including the SMILE agrienvironmental model (Hynes et al., 2009a) and the SMILE health model (Morrissey et al., 2008; 2010; 2013)

A simpler version of simulated annealing is the quota sampling method of Farrell et al. (2013). It is a probabilistic reweighting methodology whereby survey data are reweighted according to key constraining totals, or 'quotas', for each local area. In its simplest form, it randomly orders the micro data and then samples until the quotas characterised by the constraint variables are filled. The unit of analysis consists of individuals grouped into households while the constraints can be either at the individual or household level. This reweighting process is apportioned into a number of iterations, whereby an ordered repeated sampling procedure followed by the controlled broadening of constraining criteria allows for the marginal totals of census tables to be met with improved accuracy and computational efficiency. Constraints are generated from small area census data. Using these constraints, all eligible candidate households are extracted from the survey data. Fundamental to the quota sampling method is the random sorting and that the intrahousehold variation will cumulate in a random sort to result in relatively consistent aggregate totals consistent with the constraints. As a result it does not need to consider all possible combinations as in previous applications of combinatorial optimisation. Rather the "swapping" that simulated annealing requires is not undertaken until the constraints are nearly reached. It is thus analogous to the type of quota sampling undertaken by market researchers. 
O’Donoghue et al., (2013a) list a number of criteria that the model must provide;

- Link both types of data either through sampling or simulation

- Have the capacity to handle units of analyses of interest, either individual, household or a combination of the two

○ Be computationally efficient

- Be computationally transparent

- Minimise validation error.

Iterative Proportional Fitting (IPF) is quite a fast, easy to use algorithm. However, although not impossible, it is difficult to utilise the method when the unit of analysis of the constraint and the micro data are different. Using Monte Carlo simulation to generate data, it only produces micro data for variables that are contained in the constraints. Huang and Williamson (2001) in a comparison between Simulated Annealing and IPF found the former to have less simulation variability, to be more reliable, more flexible, less complex and time consuming to program. Deterministic reweighting also has the advantage of ease of use and computational efficiency. In addition it replicates the same results each time. While generating weights where the unit of analysis of the constraints and the micro data are the same is straightforward, multiple units of analysis require non-trivial methods such as generalised regression weight based methods to generate the weights. As outlined above, a point to note is that weights will be non-integer and may be less than 1, particularly where the small area population is smaller than the micro survey being used to sample. One therefore requires a stochastic truncation method to determine which micro-units are selected. Williamson (2009) highlights that when there are large numbers of constraints that the GREGW'T algorithm does not always converge; "this 'non-convergence' of the algorithm is triggered by matrix singularity, making the matrix inversion required for a numerical solution impossible. In addition, GREGW'T is sensitive to the consistency of the local area counts used as constraints, in the same way as IPF. Inconsistent constraints will also trigger non-convergence."

The main advantage of simulated annealing is that it uses real microdata to generate small area population data rather than using joint probabilities to created microdata as in IPF. Furthermore, because IPF uses probabilities to create synthetic micro data rather than using real data from a survey it can produce some unrealistic results (Norman, 1999). It also has the advantage of being able to combine data and constraints with different units of analysis. Simulated annealing's major advantage over other methods (such as iterative proportional fitting (IPF) and genetic algorithms) is an ability to avoid becoming trapped at local minima. It is also less sensitive to convergence 
issues. Tanton and Williamson (2014) found that in an Australian simulation, it performed slightly better at matching than GREGWT for both constraint variables and unconstrained variables. This was particularly the case in districts where there was no convergence.

The main disadvantage of simulated annealing however is its computational intensity (Pritchard and Miller, 2008). One of the reasons for the long run times in simulated annealing is the degree to which we test to see if new combinations of households improve the fit. Having said this, a number of SA algorithms are now available to download free from the Internet ${ }^{1}$ and once the matching datasets are structured in a manner that can be read by the programming language being employed, the synthetic data can be produced without too much "reinventing the wheel". Furthermore, quota sampling, a subset of SA by having less iteration in developing the appropriate sample, trades accuracy for computational efficiency (Farrell et al., 2013).

There are many choices when developing models, such as the choice and order of constraint variables or whether one should sample within sub-national areas. Huang and Williamson (2001) highlight that there is little analysis of the simulation properties of these various methods and how they impact on model performance. To pursue this further, Smith et al., (2009) vary the constraint variables, the order in which they are reweighted and the initial weights and propose that it may be more beneficial to apply a set of models where the small areas are "grouped into similar non-geographical ‘clusters' by population socio-demographic characteristics”.

\subsection{Validation and calibration}

The key to having confidence in a microsimulation model is adequate validation and evaluation of the matching or data generation process. Cohen (1991) in a discussion of the validation of US microsimulation models highlighted the limited extent of validation within the field. More recent application of spatial microsimulation has seen an extensive validation literature developed (Voas and Williamson, 2000; Morrissey et al., 2013; Smith et al., 2009; Edwards and Clarke, 2011). When we undertake our validation, we are undertaking two tasks. Firstly we are testing whether the relationship between constraint variables $\mathrm{X}$ and the desired variables has been maintained. This is essentially a confirmation that the spatial relationship of overlapping variables is maintained and that the core functioning of the match has been successful. Secondly, we require confirmation of the conditional independence assumption, that non-overlapping variables $\mathrm{Y}$ and $\mathrm{Z}$ in the host and target datasets are actually independent. Caldwell (1996) suggests several methods that may be used to validate the outputs from a microsimulation model. These methods include:

- In-sample Validation 
○ Out-of-Sample Validation

○ Multiple-module Validation.

In-sample validation assesses the predictive power of the model in describing the data on which it was estimated. This is akin to testing the $\operatorname{Cov}(X, Y)$ and $\operatorname{Cov}(X, Z)$ in the new spatial dataset. While this is not necessarily a major issue in many statistical models, given the computational challenges in generating data, this is a particular challenge within spatial microsimulation modelling. As a result significant emphasis is placed on this (Chin and Harding, 2006). In-sample validation may be carried out using statistical methods, such as $z$-scores, $\mathrm{z}^{2}$-scores, and total absolute error statistics (Voas and Williamson, 2000; Hynes et al., 2009b). In-sample validation may be used when the variables that are synthetically created previously co-existed or 'overlapped' each other in a dataset.

A weakness of in-sample validation is that it fails to compare the newly created data with external data (Caldwell, 1996). Out-of-sample validation involves comparing the synthetically created microdata with new, external data. However, comparable exogenous data at the same level of aggregation is not always available. This is especially problematic for aspatial microsimulation models. However, with regard to spatial microsimulation models, model outputs may be aggregated or disaggregated to levels where exogenous data is available. Birkin and Clarke (1988), Smith et al. (2009) and Edwards and Clarke (2009) and Tanton et al. (2011) used out-of-sample validation by re-aggregating estimated data sets to levels at which observed data sets already existed and compared the estimated distributions with the observed. Out-of-sample validation like this is often difficult in spatial microsimulation as frequently there is no single source of external data. However, experiencing this issue, Morrissey et al., (2008; 2010) and O'Donoghue et al. (2013a) validated their simulated data by using another spatially represented sample at a more aggregated spatial scale. Wachter et al. (1997) undertook out-of-sample validation comparing model simulations with survey data collected subsequently. Edwards and Clarke (2009) and Holm et al., (2002) describe a number of methods for testing the validation of a spatial model that involved regressing actual versus simulated variables. ${ }^{2}$ Finally, multiple-module validation refers to a technique whereby the interaction between two or more synthetically created variables is validated against pre-existing data on the interaction of these processes (Caldwell, 1996). This method of validation has been under-utilised to date.

While most validation techniques focuses on constrained or overlapping variables, there is relatively little focus on non-overlapping variables (Caldwell, 1996). Chin and Harding (2006) in 
their three stage validation procedure undertake a significant degree of validation on nonoverlapping variables and therefore implicitly test for conditional independence. Smith et al. (2009) discuss their validation of non overlapping variables in detail and provide an appendix in relation to the validation they have undertaken. In addition, there is also a disproportionate emphasis on "success stories" with relatively little focus on validation difficulties. There are exceptions, where Chin and Harding (2006) highlight some of the issues associated with nonconverging districts. Edwards et al. (2011) provides an interesting analysis of external validation in relation to obesity by comparing external cancer sites known to be correlated with obesity.

One alternative to validation is to vary the sampling constraints by changing the types of variables or the number of variables as constraints (see Smith et al., 2009). This choice however is potentially costly from a computational perspective, particularly with regard to SA. Morrissey and O’Donoghue, (2011) and Morrissey et al., (2013) describe a method based upon the dynamic microsimulation literature ${ }^{3}$ that adjusts data where there are problems with out of sample validation by spatially calibrating binary choice equations to external data. O'Donoghue et al. (2013a) uses this methodology to simulate the spatial impact of an economic downturn. Morrissey et al. (2013) developed a related method for spatially calibrating count data models. Winder (2000) critiques alignment or calibration as "an indefensible fiddle which, [and] to use Popper's celebrated phrase, effectively "immunises the model against empirical refutation"'”. It is also a critique that could be levelled against other synthetic data generation, reweighting or indeed weighting techniques as these too synthetically adjust data to calibrate against external totals. However in the absence of data that incorporates the spatial heterogeneity desired in these models, it is hard to see an alternative. Although of course one must use these methods with one's eyes open, aware to the pitfalls and criticisms of the approach.

In addition to validation issues associated with status or discrete variables, there are also issues that relate to the validation of continuous variables. This is a particular challenge as income variables are usually not included within the spatial constraint dataset. As a result spatial microsimulation models often attempt to synthetically generate the spatial distribution of income. Morrissey and O'Donoghue (2013) found that even where constraint variables have a high explanatory power, there is often still unexplained residual spatial heterogeneity. The implication of this is that while the models may explain the rank of areas reasonably well, the resulting spatial distribution may be too narrow, missing out on the spatial extremes. Morrissey and O'Donoghue (2013) utilised external data to further calibrate incomes, but it is an issue that should be borne in mind when generating income data. An exception is the Australian models (see Tanton et al., 
2011), where as household income is collected in the Census the constraint data can better capture this spatial heterogeneity.

\subsection{Dynamic versus static}

Like national scale models another choice is whether to age the population or not. Within this decision, model builders face a choice as to whether to statically age or dynamically age the population. Aging within a microsimulation context may be defined as the process of updating a database to represent current conditions or of projecting a database for one or more years to represent expected future conditions. Immervoll et al. (2005) describe the process of static ageing or adjusting the weights of the population to correspond to the changes over the relevant period. They define 'static' ageing techniques as methods attempting to align the available micro-data with other known information (such as changes in population aggregates, age distributions or unemployment rates), without modelling the processes that drive these changes (e.g., migration, fertility, or economic downturn). Static ageing thus takes macro-aggregates and then adjusts the underlying distribution to produce projections of the population distribution over time.

On the other hand, dynamic ageing (O’Donoghue, 2001) involves the estimation of a system of econometric equations and then simulates changes in the population. It is an ageing procedure that takes a sample of a population underlying characteristics $\mathrm{X}$ and holds them constant. The weights given to different parts of the sample are then changed through the use of a dynamic simulation mechanism to produce different weighted distributions corresponding to expected characteristics in the future. Dynamic ageing will consistently estimate characteristics of the projected income distribution, under ideal circumstances in which all transition probabilities and state specific expectations can themselves be estimated consistently.

Both methodologies have advantages and disadvantages. As such, neither approach should be used in isolation. Dynamic ageing by focusing on the individual takes no account of processes at the level of the market such as labour demand. Furthermore, dynamic ageing has huge computational requirements in terms of data and modelling to jointly estimate all the required processes. However in a dynamic model, the joint estimation of work and life histories is a formidable requirement given the available data. Therefore, it is necessary to assume that the marginal distributions of different processes are independent (O'Donoghue, 2001). Static ageing has a number of theoretical objections. Firstly, static ageing cannot be used where there are no individuals in the sample in a particular state. If there are a small number of cases of a particular household category, a very high weight may have to be applied, resulting in unstable predictions. 
Changing demographic and economic trends over time may mean that increasing weight is placed on population types with very few cases in the sample (Klevmarken 1997). Secondly, static ageing procedures are relatively well suited to short to medium term forecasts where changes in the structure of the population are small. However, over longer periods of time or over more turbulent periods, it may be more difficult to use static ageing due to changing characteristics of the population.

Ageing the population within spatial microsimulation models have employed a variety of different methods. These can fully dynamically age a spatial base dataset as in the case of the SVERIGE model (Rephann et al., 2005) or the original SMILE model (Ballas et al., 2005a). The database employed in SVERIGE to estimate the equations and simulate the population is called TOPSWING (Total Population of Sweden Individual and Geographical database), a longitudinal database, which contains information on all Swedish residents including the location of residents in co-ordinates accurate to 100 meters (Vencatasawmy et al., 1999). The SMILE dataset meanwhile was synthetically generated using methods described above. These models take a $100 \%$ population sample and dynamically age it using a series of equations over time. The computational requirements of these models are huge. While the requirements are very significant for standard dynamic models the cost is multiplied as the base datasets are typically multiples in size, thus requiring either enormous computing power as in the case of the SVERIGE model or having a relatively simple system of equations as in the case of SMILE.

Another challenge of dynamic ageing spatial microsimulation models is to have spatial heterogeneity within the behavioural processes. While systems of equations with nationally representative behaviour are not unusual, incorporating spatial heterogeneity in these equations requires that we have spatially representative panel or administrative data on which to estimate the equations. It is rare, except in the case of administrative data that such data are available. Another challenge when reweighting methods have been used to generate the base data in the first instance is that the weights may vary over time. For example, over time, a household can form or dissolve. As a result, it may no longer make sense to maintain the original weight. Deweighting the data, by replicating households in proportion to the weights can resolve this issue. It is less clear what one can do when weights are less than 1, although perhaps one could take random draws, which of course will change the base population.

Dynamic spatial microsimulation models with a narrower scope, for example a city, pose less serious computational challenges. In the MOSES model, Wu et al. (2008) age a population of students over time within the city of Leeds. Transport and land use models with a focus on inter- 
temporal movement can be classified as dynamic microsimulation models. Like the MOSES model, they also tend to utilise a narrower spatial scope, typically a city or urban area (Zhao and Chung, 2006; Waddell, 2002, Weidner et al., 2007).

An alternative method of dynamically ageing a population is utilised by Anderson et al. (2007). They firstly dynamically age a national population and then use static spatial microsimulation reweighting techniques to generate the spatial population. A variant of this approach was utilised in SimBritain, which was developed to simulate the population of Britain at different geographical scales from 1991 up to the year 2021 (Ballas et al., 2005b). Data from the British Household Panel Survey was statistically matched together to form a longer panel and then reweighting techniques were applied to generate a spatial dataset. Some models utilise static ageing of the control totals as in the case of Australia (Vidyattama et al., 2013) or in the case of O'Donoghue et al. (2012) where the model is "now-casted" to the present to account for the impact of the economic downturn via the external control totals.

While the scope of these models can vary from country to city, the time horizon and period of analysis can also vary. The time horizon is the inter-temporal scope such as 10 years, 20 years, 24 hours etc, while the period of analysis refers to the time unit over which the model increments such as year, month, day or hour. In the models that focus on household welfare (such as Rephann et al., 2005; Ballas, et al., 2005a; Anderson et al., 2007), the time horizon is typically multi-annual and the period of analysis is typically the year. This may also be the case with land use models as with Alberti and Waddell (2000). At the other extreme, the time horizon for transport models may be as short as a 24 hour period, with the period of analysis continuous time, tracking travel behaviour (e.g. Xu et al., 2003).

\subsection{Simulating Change}

A significant opportunity for spatial microsimulation models is to incorporate behaviour or the simulation of alternative realities or policies. Models that do not incorporate behavioural change, essentially model the stock of the relevant characteristic. The types of ex ante simulations that have taken place in the spatial microsimulation literature vary from deterministic simulations to complex behavioural simulations based upon calibrated, estimated or theoretical agent based modelling approaches. In this section, we discuss models that simulate changes to spatial datasets, generated or otherwise.

Akin to the static microsimulation modelling literature, a number of models such as those 
developed in NATSEM, Australia (Harding et al., 2009) the University of Leeds, UK (Ballas et al., 2003) and Ireland (O'Donoghue et al., 2013a) have linked static tax-benefit microsimulation models to spatial microsimulation models. In these cases no behavioural reaction is modelled. Rather the simulated impact is equivalent to the "day after" effect. Although an important objective of social sciences is to understand behavioural reactions, given the complexity of these policies any form of impact modelling is often useful in the absence of a behavioural analysis.

In a survey of dynamic microsimulation models, O'Donoghue (2001) classified behavioural models into statistical or behavioural models. Statistical models are based upon associative relationships between behavioural outcomes and demographic and other characteristics. Behavioural models on the other hand try to incorporate structural behaviour, responding for example to policy or economic changes. These choices also exist in spatial microsimulation. Behavioural models can also incorporate theoretical based agent based models. Van Wissen's (2000) firm level model provides an example of a model based around statistical associations. Various behaviours such as births, closures and relocations of firms are modelled as a function of firm and other characteristics. Rephann et al., (2005) utilise statistical models to assess the impact of a labour market shock, examining the spatial impact of a closure of a car plant utilising a number of statistical relationships.

Behavioural models incorporate structural equations, which contain factors that directly impact on behaviour. For example travel models such as Hunt and Stefan (2007) contain information about time and distance associated with different travel choices and estimate a structural preference model based upon a stated preference survey. A variant of this methodology is a spatial interaction model, which tries to understand spatial choices such as work-residence or retail-residence choices. Nakaya et al. (2007) describe a spatial interaction model of retail behaviour in Japan, which relates consumer flows, to store attractiveness, distance to store, the potential supply of consumers and household characteristics. Ballas et al. (2006) developed a spatial interaction model of journey to work and used it to identify the location of workers of a major engineering plant closure. Van Leeuwen, et al. (2009) utilised a utility framework to incorporate choice specific attributes (floor space and distance) to model retail behaviour in small towns in the Netherlands. Land use models such as Miller et al. (2004) have started to bring together a wide range of transport related behaviour such as travel choice, car ownership and mode together and land use behaviour such as locational choice, to model the consequential economic flows. Wu et al. (2008) utilise a spatial interaction model to simulate migration of students. 
While often Agent Based Modelling (ABM) is used interchangeably with statistical or behavioural microsimulation, a common differentiation is that $\mathrm{ABM}$ tend to have a greater focus on behaviour and may use theoretical frameworks to inform behavioural choices, while MSM's tend to have a lower behavioural focus and rely on data for estimation purposes (Hassan et al., 2008). Wu et al. (2008) highlighted some problems associated with using standard spatial interaction models and proposed utilising $\mathrm{ABMs}$ to improve the localised representation of the student specific characteristics. Sivakumar (2007) argues that agent-based micro-simulation modelling represents the best approach currently available to modelling large, complex, dynamic, agentbased socio-economic systems such as an entire region. Sivakumar (2007) argues that agent based microsimulation models reduce model aggregation bias, enhance behavioural fidelity and enable future evolutions to be estimated due to their path-dependent patterns, which may not be well captured by conventional spatial microsimulation models.

An approach to modelling change that has not been explored yet in the published literature is the potential linkage between spatial microsimulation models and Computable General Equilibrium Models (CGE). While there is a substantial literature linking static microsimulation models with CGE models (Ahmed and O'Donoghue, 2007), there are opportunities in linking spatial models, particularly when the impact on the wider economy is important. One application of linking a CGE to microsimulation to spatial microsimulation model is shown in another paper in this special issue (Vidyattama et al., 2014). However there remain challenges in modelling the spatial incidence of potential feedback effects and this was not done in this paper.

\section{SUMMARY AND DISCUSSION}

In this paper we reviewed the development, use and characteristics of microsimulation models that incorporate a spatial dimension. Location is important from the perspective of a comparative analysis, analysing issues that require location attributes such as the environment or distance, analysing policy that is spatially heterogeneous or focuses on local scale such as on a city, town or village. Spatial microsimulation models have a number of advantages over aspatial microsimulation models (Ballas and Clarke, 2001c), enabling a place based analyse to be incorporated in people focused analyses (Miller, 2007). Given these advantages, it is surprising that spatial microsimulation models are not used more frequently (Clarke, 1996). However, the development of spatial microsimulation models requires substantial additional time and resource investment (Haveman and Hoolenbech, 1980). This is particularly the case when accessing or generating spatially referenced micro-data. The generation of spatially representative data is a 
significant challenge for the field and consequentially much of the research is devoted to this.

A significant body of literature has developed with applications in demography, welfare analysis, health, regional development, transport planning, land use planning, natural resources analysis, crisis planning and other public policy analysis. This paper summarises some of the main analyses in these dimensions. In surveying the spatial microsimulation literature, we reviewed models under a number of dimensions including scope and spatial disaggregation, data sources, data creation methodologies, validation and calibration and modelling change. As a social science methodology, there has been a relatively small focus on the simulation of behavioural change. Part of the reason for this is that there are relatively few agreed standards in relation to the development of the models, slowing the development as basic infrastructure has to be developed first. This is similar to other branches of microsimulation (O'Donoghue, 2001). Thus spatial microsimulation models had been criticised for being poorly validated (or difficult to validate), poorly documented, too slow, and encompassing too few real-life applications (Holm et al. 1996). However recent developments have seen many of these criticisms reduced or over come (O’Donoghue et al., 2013a, Tanton et al., 2009, Ballas et al., 2005c).

The development of standard open source tools for data generation as in the case of other simulation fields such as Agent Based Modelling, may enable model developers to progress through the data generation phase more quickly. Furthermore it may allow more behavioural change to be incorporated within the models. This could perhaps be done via the linkage with other regional modelling methods (Isard et al., 1998). However a counter-balancing argument to adding further dimensions such as behavioural response is complexity. Complexity can arise in different dimensions, including the characteristics of the population, the extent of the potential behaviours or the frequency, the time length of the potential behaviours and the interactions with the spatial dimension. Models abstracting from the real world help to provide insights from complex systems. Increasing complexity may increase the cost of validating them and lead to an over simplification of processes in order to become more integrated.

Many of Lee's (1973) criticisms in his "Requiem for Large-Scale Models" are still relevant today. His "seven sins", are that large models are computationally intensive, data hungry, make extreme demands on our theoretical understanding of urban spatial processes and our methodological capabilities for capturing that understanding within operational computer code, and are difficult to estimate and validate. These criticisms are relevant for spatial microsimulation models too. The future therefore may not necessarily be one of bigger and more complicated models, but perhaps more focused on deeper more targeted models. 


\section{REFERENCES}

Ahmed, V. and C. O’Donoghue, (2007). "CGE-Microsimulation Modelling: A Survey”, MPRA Discussion Paper No. 9307.

Alberti, M. and Waddell, P., (2000). An Integrated Urban Development and Ecological Simulation Model, 2000, Integrated Assessment.

Alderman, H., Babita, M., Demombynes, G., Makhatha, N., and Ozler, B. (2002) How Low Can You Go?: Combining Census and Survey Data for Mapping Poverty in South Africa," Journal of African Economics, Vol. 11, pp 169-200.

Anderson, B., (2007). Creating Small Area Income Estimates for England: spatial microsimulation modelling University of Essex Chimera Working Paper Number: 2007-07.

Anderson, B., Paola De Agostini, P. Laidoudi, S., Weston, A. and Zong, P. (2007), Time and Money in Space. University of Essex Chimera Working Paper Number: 2007-09.

Ballas, D. and Clarke, G.P., (2000). 'GIS and microsimulation for local labour market policy analysis', Computers, Environment and Urban Systems, Vol. 24, pp. 305-30.

Ballas D, Clarke G.P., Turton I. (2003). A spatial microsimulation model for social policy evaluation. In Modelling Geographical Systems, Boots B, Thomas R (eds): Kluwer: the Netherlands, Kluwer; 143-168.

Ballas, D., (2004). Simulating trends in poverty and income inequality on the basis of 1991 and 2001 census data: a tale of two cities. Area Vol. 36.2, pp. 146-163.

Ballas D, Clarke G.P., (2001a), "Modelling the local impacts of national social policies: a spatial microsimulation approach" Environment and Planning C: Government and Policy 19(4) 587 606.

Ballas, D. and Clarke, G.P., (2001b). 'Towards local implications of major job transformations in the city: a spatial microsimulation approach', Geographical Analysis, Vol. 33, pp. 291-311

Ballas, D., Clarke, G.P. and Wiemers, E. (2005a). Building a dynamic spatial microsimulation model for Ireland, Population, Space and Place, 11, 157-172.

Ballas, D., Clarke, G.P., Dorling, D., Eyre, H., Thomas, B., and Rossiter, D., (2005b). SimBritain: 
a spatial microsimulation approach to population dynamics. Population, Space and Place 11, 1334.

Ballas, D., Rossiter, D. Thomas, B., Clarke, G. and Dorling, Danny, (2005c). Geography matters: Simulating the local impacts of national social policies. Joseph Rowntree Foundation.

Ballas, D. Clarke, G.P. and Dewhurst, J., (2006). Modelling the Socio-economic Impacts of Major Job Loss or Gain at the Local Level: a Spatial Microsimulation Framework. Spatial Economic Analysis,Vol. 1 No. 1, pp. 127 - 146.

Ballas, D., Clarke, G. P., Dorling, D. and Rossiter, D. (2007). Using SimBritain to Model the Geographical Impact of National Government Policies. Geographical Analysis 39(1), 44-77.

Ballas, D., Clarke, G.P., Wiemers, E., (2006). Spatial microsimulation for rural policy analysis in Ireland: The implications of CAP reforms for the national spatial strategy. Journal of Rural Studies Vol. 22 pp 367-378.

Ballas, D., \& Clarke, G. P. (2009). Spatial microsimulation. Handbook of spatial analysis. Sage, London, 277-298.

Baulch, B. and Minot, N.,(2006) Poverty mapping with aggregate census data. International Food Policy Research Institute (IFPRI) MTID discussion papers No. 49.

Baschieri, Angela, Jane Falkingham Duncan Hornby, Craig Hutton, (2005). Creating a Poverty Map for Azerbaijan, World Bank Policy Research Working Paper 3793.

Bell, P. (2000). Weighting and standard error estimation for ABS household surveys. ABS Methodology Advisory Committee: Australian Bureau of Statistics.

Benenson, I., (2007). Editorial: WARNING! The scale of land-use CA is changing! Computers, Environment and Urban Systems. 31, 107-113.

Bennett, V.J., M. Beard, P. A. Zollner, E. Fernandez-Juricic, L. Westphal, C.L. LeBlanc (2009). Understanding wildlife responses to human disturbance through simulation modelling: A management tool. Ecological Complexity, Vol. 6 pp. 113 - 134.

Benson, T., (2005). An investigation of the spatial determinants of the local prevalence of poverty in rural Malawi, Food Policy, Vol. Vol 30., pp 532-550. 
Benson, T., (2006). Insights from poverty maps for development and food relief program targeting. IFPRI Food Consumption and Nutrition Division, Discussion Paper 205.Birkin M, Clarke M., (1985). Comprehensive dynamic urban models: integrating macro- and microapproaches. in: Griffith DA, Haining RP (eds) Transformations through space and time: an analysis of nonlinear structures, bifurcation points and autoregressive dependencies. Martinus Nijhoff, Dordrecht, pp 165.292

Birkin M., Wu, B. and Rees, P., (2009). "Moses: Dynamic Spatial Microsimulation with Demographic Interactions" in P. Williamson, A. Zaidi and A. Harding (eds) New Frontiers in Microsimulation Modelling; Ashgate.

Birkin, M., \& Clarke, G. (1985). On the Design and Implementation of an Information System for Urban Modelling and Spatial Planning. School of Geography, University of Leeds.

Birkin, M., \& Clarke, M. (1988). SYNTHESIS-a synthetic spatial information system for urban and regional analysis: methods and examples. Environment and planning A, 20(12), 1645-1671.

Birkin M, Clarke G (2012). The enhancement of spatial microsimulation models using geodemographics, Annals of Regional Science, 49, 515-532.

Bhat, C.R., Guo, J.Y., Srinivasan, S., and Sivakumar, A., (2004). "A Comprehensive Econometric Microsimulator for Daily Activity-Travel Patterns (CEMDAP)," Transportation Research Record, Vol. 1894, pp. 57-66.

Bradley, M. and Bowman, J., (2006). A Summary of Design Features of Activity-Based Microsimulation Models for U.S. MPOs, White Paper for the Conference on Innovations in Travel Demand Modeling, Austin, TX, May.

Brouwers, L. (2005). MicroPox: A Large-Scale and Spatially Explicit Microsimulation Model for Smallpox Planning. In Ingalls, V., (editor), The Proceedings of the 15 th International Conference on Health Sciences Simulation, pages 70.76, San Diego, USA. SCS.

Brouwers, L., Ekenberg, L., and Hansson, K., (2004). Multi-criteria decision-making of policy strategies with public-private re-insurance systems. Risk Decision and Policy, Vol. 9, pp. 23-45.

Caldwell, S. (1996). Health, wealth, pensions and life paths: The CORSIM dynamic microsimulation model. Contributions to Economic Analysis, 232, 505-522. 
Cataife, G. (2014). Small area estimation of obesity prevalence and dietary patterns: A model applied to Rio de Janeiro city, Brazil. Health \& place, 26, 47-52.

Chen, X., Meaker, J.W. and Zhan, F.B., (2006). Agent-Based Modeling and Analysis of Hurricane Evacuation Procedures for the Florida Keys. Natural Hazards Vol. 38 pp. 321-338.

Chin, S-F, Harding, A, Lloyd, R, McNamara, J, Phillips, B, Vu, Q, (2005). Spatial Microsimulation Using Synthetic Small-area Estimates of Income, Tax and Social Security Benefits. The Australasian Journal of Regional Studies, Volume 11 Issue 3.

Chin, S. F., \& Harding, A. (2006). Regional dimensions: creating synthetic small-area microdata and spatial microsimulation models. National Centre for Social and Economic Modelling.

Clancy, D., Breen, J., Butler, A.M., Morrissey, K., O’Donoghue, C. and Thorne, F. (2013). "Modelling the location economics of biomass production for electricity generation" in $C$. O'Donoghue, S. Hynes, K. Morrissey, D. Ballas and G. Clarke, Modelling the Local Economy: A Simulation Approach. Springer Verlag.

Clarke, G. (1996) Microsimulation for urban and regional policy analysis, Pion, London, 64-87.

Clarke G., Kashti A., McDonald A. and Williamson P. (1997) 'Estimating small area demand for water: a new methodology', Journal of the Chartered Institution of Water and Environmental Management, 11, 186-192.

Clarke, M., Keys, P., and Williams, H. (1979), Household dynamics and economic forecasting: a microsimulation approach, Working Paper 257, School of Geography, University of Leeds.

Clarke, M., Keys, P., and Williams, H. (1980), Micro-simulation in socio-economic and public policy analysis, Working Paper 278, School of Geography, University of Leeds, http://www.popline.org/docs/0542/011077.html

Cohen, M.L. (1991), Evaluations of Microsimulation Models: Literature Review. In Citro, C. F., \& Hanushek, E. A. (Eds.). Improving Information for Social Policy Decisions: Review and recommendations (Vol. 1). National Academies Press.

Cullinan, J., Hynes, S., \& O'Donoghue, C. (2008). Estimating catchment area population indicators using network analysis: an application to two small-scale forests in County Galway. Irish Geography, 41(3), 279-294. 
Cullinan J, Hynes S, O'Donoghue C (2011), Using Spatial Microsimulation to Account for Demographic and Spatial Factors in Environmental Benefit Transfer, Ecological Economics, 70, 813-824.

Davis, B., (2003). Choosing a Method for Poverty Mapping. Rome: Food and Agriculture Organization of the United Nations.

Decoster, A. , K De Swerdt, J Loughrey, C O’Donoghue and D Verwerft (2009) Imputation of expenditures into the income datasets of five European countries. Deliverable 3.5, EUROMOD-AIMAP Project. http://www.iser.essex.ac.uk/files/msu/emod/aimap/deliverables/AIM-AP3.5.pdf

De Palma, A., and Marchal, F., (2002). METROPOLIS Tool-Box: An Advocacy for Large-Scale Mesoscopic Transportation Systems. Networks and Spatial Economics, 2: 347.369.

Deming, W.E. and Stephan, F. F. (1940). On a least square adjustment of a sampled frequency table when the expected marginal totals are known. Annals of Mathematical Statistics, 11(4):427_ 444, December.

Doherty, S.T. and. Miller, E.J. (2000). A computerized household activity scheduling survey. Transportation 27: 75-97.

Edwards, K.L., and Clarke G.P. (2009). The design and validation of a spatial microsimulation model of obesogenic environments for children in Leeds: SimObesity, Social Science and Medicine, 69(7), 1127-1134.

Edwards, K. L., Clarke, G. P., Thomas, J., \& Forman, D. (2011). Internal and external validation of spatial microsimulation models: Small area estimates of adult obesity. Applied Spatial Analysis and Policy, 4(4), 281-300.

Elbers, C., Olsen Lanjouw, J., and Lanjouw, P. (2003). Micro-Level Estimation of Poverty and Inequality. Econometrica, Vol. 71, No. 1, pp. 355-364.

Elbers, C., Lanjouw, P. and Leite, P.G. (2008). Testing the Poverty Map Methodology in Minas Gerais. World Bank Policy Research Working Paper 4513.

Eliasson, J. and Mattsson, L.G. (2006). Equity Effects of Congestion Pricing Quantitative Methodology and a Case Study for Stockholm. Transportation Research Part A: Policy and Practice, 
Volume 40, Issue 7, Pages 602-620.

Farrell, N., Morrissey, K., \& O’Donoghue, C. (2013). Creating a Spatial Microsimulation Model of the Irish Local Economy. In Spatial Microsimulation: A Reference Guide for Users (pp. 105-125). Springer Netherlands.

Felsenstein, D., Ashbel, E. and Ben-Nun, A., (2007). Microsimulation of Metropolitan Employment Deconcentration: Application of the UrbanSim model in the Tel Aviv region, in Koomen, E., Stillwell, J., Bakema, A. and Scholten, H.J. (eds.) Modelling Land-Use Change Progress and Applications. The GeoJournal Library.

Franklin, Joel P. (2005) Nonparametric Distributional Analysis of a Transportation Policy: Stockholm's Congestion Pricing Trial. Paper presented as a poster at the Transportation Research Board 84th Annual Meeting, Washington, DC. 2005.

Gräb, J. and Grimm, M., (2008). "Spatial inequalities explained - Evidence from Burkina Faso," Ibero America Institute for Econ. Research (IAI) Discussion Papers 173, Ibero-America Institute for Economic Research.

Grist, N. R. (1979). Pandemic influenza 1918. British medical journal, 2(6205), 1632.

Hägerstrand, T., (1957). Migration and Area, in Migration in Sweden: a Symposium. Lund Studies in Geography. Series B, Human Geography N. 13. Lund, Sweden, C.W.K. Gleerup.

Hägerstrand, T., (1967). Innovation diffusion as a spatial process. Translated by A. Pred. Chicago: University of Chicago Press.

Hanaoka K. and Clarke G.P., (2007). Spatial microsimulation modelling for retail market analysis at the small-area level, Computers, Environment and Urban Systems, 31, 162-187.

Harding, A, Lloyd, R, Bill, A and King, A (2006), 'Assessing poverty and inequality at a detailed regional level: New advances in spatial microsimulation' in M. McGillivray and M. Clarke, (eds), Understanding Human Well-being. Helsinki, United Nations University Press, vol. pp. $239-261$.

Harding, A., Vu, N. Q., Tanton, R., and Vidyattama, V. (2009), 'Improving work incentives and incomes for parents: the national and geographic impact of liberalising the Family Tax Benefit income test', Economic Record, Vol 85, September, S48-S58. 
Hassan, S., Pavon, J. and Gilbert, N. (2008). Injecting Data into Simulation: Can Agent-Based Modelling Learn from Microsimulation? The Centre for Research in Social Simulation Mimeo.

Haveman, R. H., \& Hollenbeck, K. (Eds.). (1980). Microeconomic Simulation Models for Public Policy Analysis: Distributional Impacts (Vol. 1). Academic Press.

Hennessy, T., Shrestha, S. and Hynes, S.P. (2007). The Effect of Decoupling on Farming in Ireland: A Regional Analysis. Irish Journal of Agricultural \& Food Research Vol 46 no 1.

Hentschel, J., Lanjouw, J. O., Lanjouw, P., \& Poggi, J. (1999). Combining census and survey data to study spatial dimensions of poverty: A case study of Ecuador. World Bank Economic Review.

Hentschel, J., Lanjouw, J. and Lanjouw, P., (1998). Combining census and survey data to study spatial dimensions of poverty. World Bank Policy Research Working Paper Series No. 1928.

Hermes, K. and Poulsen, M., (2012) A review of current methods to generate synthetic spatial microsdata using reweighting and future directions. Computers Environment and Urban Systems. Vol. 36, pp. 281-290.

Hollander, Y. and Liu, R., (2008). The principles of calibrating traffic microsimulation models. Transportation 35:347-362.

Holm, E., Lindgren, U., Mäkilä, K. and Malmberg, G., (1996) Simulating an entire nation, in G Clarke (ed) Microsimulation for urban and regional policy analysis, Pion, London, 64-87.

Holm, E., Holme, K., Mäkilä, K., Mattsson-Kaupi, M. and Mörtvik, G. (2002): The SVERIGE spatial microsimulation model - Content, validation, and example applications. Gerum Kulturgeografi 2002:4, Umeå Universitet.

Holm, E., Lingren, U., Makila, K., Malmberg, G. (1996). Simulating an entire nation. In European Research in Regional Science 6. Microsimulation for Urban and Regional Policy Analysis (ed. G.P. Clarke). London: Pion.

Hooimeijer, P. (1996). A life course approach to urban dynamics: state of the art in and research. In G.P. Clarke (Ed.), Microsimulation for Urban and regional Policy Analysis (pp. 28-64). London: Pion Limited.

Hooimeijer, P. and Oskamp, A., (2000). Locsim: microsimulation of households and housing market. Paper delivered at the 10th Biennial Conference of the Australian Population Association, 
Melbourne 28th November to 1st December.

Hoshen, M.B., Burton, A.H. and Bowcock T.J.V. (2007). Simulating disease transmission dynamics at a multi-scale level, International Journal of Microsimulation Vol. 1 pp. 26-34.

Huang, Z. and Williamson, P. (2001). A Comparison of Synthetic Reconstruction and Combinatorial Optimisation Approaches to the Creation of Small-Area Microdata. Department of Geography Working Paper 2001/2, University of Liverpool.

Hunt, J.D. and Stefan, K.J. (2007), Tour-based microsimulation of urban commercial movements. Transportation Research Part B 41 981-1013.

Hynes, S., Morrissey, K., O'Donoghue, C. and Clarke, G. (2009a). "A Spatial Microsimulation Analysis of Methane Emissions from Irish Agriculture.” Journal of Ecological Complexity 6: 135146.

Hynes, S., Morrissey, K., O’Donoghue, C. and Clarke, G. (2009b). "Building a Static Farm Level Spatial Microsimulation Model for Rural Development and Agricultural Policy Analysis in Ireland." International Journal of Agricultural Resources, Governance and Ecology, 8 (3): 282-299.

Hynes, S., Farrelly, N., Murphy, E. and O'Donoghue, C. (2008). "Modelling habitat conservation and participation in agri-environmental schemes: A spatial microsimulation approach." Ecological Economics, vol. 66, issue 2-3, pages 258-269.

Hynes, S., Hanley, N. and O'Donoghue, C., (2010). A Combinatorial Optimization Approach to Non-Market Environmental Benefit Aggregation via Simulated Populations. Land Economics, 86(2):345-362.

Immervoll H., O’Donoghue, C. and Sutherland, H., (1999). An Introduction to EUROMOD. EUROMOD Working Paper no. 0/99.

Immervoll H., Lindström, K, Mustonen, E and Riihelä, M (2005) Accounting for population changes in tax-benefit microsimulation models. A note on static data 'ageing' techniques, EUROMOD Working Paper EM7/05, University of Cambridge.

Isard, W., Azis, I. J., Drennan, M. P., Miller, R. E., Saltzman, S., and Thorbecke, E. (1998). Methods of interregional and regional analysis (Vol. 490). Aldershot: Ashgate.

Joshi, H., Guhathakurta, S., Konjevod, G., Crittenden, J. and Li, K. (2006). Simulating the effect 
of light rail on urban growth in phoenix: An application of the Uurbansim modeling environment, Journal of Urban Technology. Vol13(2): 91-111.

Kain, J. F., and Apgar, W. C., (1985). Housing and neighborhood dynamics. Cambridge, MA: Harvard University Press.

Kavroudakis, D., Ballas, D., and Birkin, M. (2009). Use of Spatial Microsimulation Spatial Microsimulation for public policy: The case of Education The case of Education. Paper Presented to the $2^{\text {nd }}$ General Conference of the International Microsimulation Association, Ottawa.

Kelly, S, Phillips, B and Taylor, E, (2005). Baseline small area projections of the demand for housing assistance, Final Report, AHURI.

King, A., Mclellan, J. and Lloyd, R. (2002), Regional Microsimulation for improved service delivery in Australia: Centrelink's CUSP Model. Paper Prepared for the 27th General Conference of The International Association for Research in Income and Wealth Stockholm, Sweden. August 18 - 24, 2002.

Kitamura, R., Lula, C.V and Pas, E.I (1993) AMOS: An activity-based, flexible and truly behavioural tool for evaluation of TDM measures. Proceedings of the 21st Summer Annual Meeting: Transportation Planning Methods, PTRC Education and Research Services, Ltd., London, pp. 283294.

Kitamura, R., Pendyala, R.M, Pas, E.I and Reddy, P. (1995) Application of AMOS, an ActivityBased TCM Evaluation Tool, to the Washington, D.C., Metropolitan Area. 23rd European Transport Forum: Proceedings of Seminar E Transportation Planning Methods, PTRC Education and Research Services, Ltd., London, pp. 177-190.

Klevmarken, N. A., (1997). "Modelling Behavioural Response in EUROMOD," Cambridge Working Papers in Economics 9720, Faculty of Economics, University of Cambridge.

Kongmuang, C., Clarke, G.P., Evans, A.J. and Jin, J., (2006). SimCrime: A Spatial Microsimulation Model for the Analysing of Crime in Leeds. Working Paper $r$ 06/1. The School of Geography, University of Leeds.

Kruseman, G., Blokland, P.W., Bouma, F., H. Luesink, L. Mokveld, and H. Vrolijk (2008a). Micro-simulation as a tool to assess policy concerning non-point source pollution: the case of ammonia in Dutch agriculture. Paper prepared for presentation at the 107th EAAE Seminar 
"Modelling of Agricultural and Rural Development Policies". Sevilla, Spain, January 29th February $1^{\text {st }}$

Kruseman, G., Blokland, P.W., Luesink,H., Mokveld, L., and Vrolijk, H. (2008b). Ex-ante evaluation of tightening environmental policy - the case of mineral use in Dutch agriculture. Paper prepared for presentation at the 12th Congress of the European Association of Agricultural Economists - EAAE 2008.

Kuiper, M. and Ruben, R. (2006). Poverty Targeting, Resource Degradation and Heterogeneous Endowments - A Micro-Simulation Analysis of a Less Favored Ethiopian Village. Paper Presented at the International Association of Agricultural Economists Annual Meeting, August 12-18, 2006, Queensland, Australia with number 25340.

Laird J, Druitt S \& Fraser D (1999) Edinburgh city centre: a microsimulation case-study. Traffic Engineering and Control, 40(2), 72-76.

Landis, J., and Zhang, M., (1998a). The second generation of the California urban futures model. Part 1: Model logic and theory, Environment and Planning B: Planning and Design, Volume 25, 657666.

Landis, J., and Zhang, M., (1998b). The second generation of the California urban futures model. Part 2: Specification and calibration results of the land use change module, Environment and Planning B: Planning and Design, Volume 25, 657-666.

Lee Jr, D. B. (1973). Requiem for large-scale models. Journal of the American Institute of Planners, 39(3), 163-178.

Lindgren U. (1999). 'Simulating the long-term labour market effects of an industrial investment: a microsimulation approach', Erdkunde, 53, 150-162.

Lindgren, U. and Elmquist, H., (2005). Environmental and Economic Impacts of DecisionMaking at an Arable Farm: An Integrative Modeling Approach. Ambio: A Journal of the Human Environment. Vol. 34, No. 4.5.

Lindgren, U., Strömgren, M., Holm, E. and Häggström Lundevaller, E., (2007). Analyzing SocioEconomic Impacts of Large Investments by Spatial Microsimulation. Paper presented at 1st general conference of the International Microsimulation association: Celebrating 50 years of Microsimulation. 
Liu, R. (2005) The DRACULA Dynamic Traffic Network Microsimulation Model, in Kitamura and Kuwahara (eds.) Simulation Approaches in Transportation Analysis: Recent Advanced and Challenges, pp 23-56, Springer.

Lloyd, R., Harding, A. and Hellwig, O., (2000) Regional Divide a Study of Incomes in Regional Australia, Australasian Journal of Regional Studies, Vol. 6, No. 3, 271.

Lundgren, A., (2004). Micro-Simulation Modelling of Domestic Tourism Travel Patterns in Sweden. Paper Presented to 7th International Forum on Tourism Statistics

Stockholm, Sweden, 9-11 June.

Lundevaller, E.H. , Holm, E., Strömgren, M. and Lindgren, U. (2007). Spatial dynamic microsimulation of demographic development. Paper presented at 1 st general conference of the International Microsimulation association: Celebrating 50 years of Microsimulation.

Lymer, S., Brown, L. Yap, M. and Harding, A. (2008) 2001 Regional Disability Estimates for New South Wales, Australia, Using Spatial Microsimulation. Applied Spatial Analysis. Vol. 1 pp 99-116.

Lymer, S., Brown, L., Harding, A. and Yap, M. (2009), 'Predicting the need for aged care services at the small area level: the CAREMOD spatial microsimulation model'. International Journal of Microsimulation. 2(2), Autumn, pp. 27-42.

Mavoa, S., (2007). Estimating the Social Impact of Reduced CO2 Emissions from Household Travel Using GIS Modelling. In Morris, Jenny and Rose, Geoff, Eds. Proceedings 30th Australasian Transport Research Forum (ATRF), Melbourne, Australia.

Melhuish, T., King, A., Taylor, E., (2004). The regional impact of Commonwealth Rent Assistance, Australian Housing and Urban Research Institute, Report No 71.

Metropolis, N., Rosenbluth, A., Rosenbluth, M., Teller, A. and Teller, E. (1953). Equation of state calculations by fast computing machines. Journal of Chemical Physics, Vol. 21, pp. 10871092.

Miller, E.J., Hunt, J.D., Abraham, J.E. and Salvini, P.A., (2004). Microsimulating urban systems. Computers, Environment and Urban Systems, Volume 28, Issues 1-2, January-March 2004, Pages 9-44. 
Miller, E.J. (2009). Articulating the activity-based paradigm: Reflections on the contributions of Ryuichi Kitamura. Transportation, DOI 10.1007/s11116-009-9233-9.

Miller, E. J., and Salvini, P. A. (2001b). The integrated land use, transportation, environment (ILUTE) microsimulation modelling system: description and current status, Chapter 41. In D. Hensher (Ed.), The leading edge in travel behavior research, selected papers from the 9th International Association for Travel Behaviour Research Conference, Gold Coast, Queensland, Australia, 2.5 July, 2000.

Miller, H, J (2007). Place-based versus people-based geographic information science. Geography Compass, 1(3), 505-535.

Moeckel, R., Schwarze, B., Spiekermann, K., and Wegener, M., (2007). Simulating Interactions between Land Use, Transport and Environment, Paper presented at the 11th World Conference on Transport Research, University of California at Berkeley, 24-28 June 2007.

Morrissey, K. and O’Donoghue, C. (2011). The Spatial Distribution of Labour Force Participation \& Market Earnings at the Sub-National Level in Ireland', Review of Economic Analysis, 3(1), 80-101.

Morrissey, K., Clarke, G., Hynes, S and O'Donoghue, C. (2010). Examining the factors associated with depression at the small area level in Ireland using spatial microsimulation techniques, Irish Geography, Vol. 43(1), 1-22.

Morrissey, K., Clarke, G., Ballas, D., Hynes, S., O’Donoghue, C. (2008). Analysing Access to GP Services in Rural Ireland using micro-level Analysis, Area, vol. 40(3), 354-364.

Morrissey, K and O'Donoghue C, (2013), "Validation Issues and the Spatial Pattern of Household Income", In O'Donoghue, C., Ballas, D., Clarke, G.P., Hynes, S., Morrissey, K. (Eds.), Spatial Microsimulation for Rural Policy Analysis, London, Springer.

Morrissey, K, O'Donoghue, C, Clarke, G, Li, J (2013). Using Simulated Data to examine the Determinants of Acute Hospital Demand at the Small Area Level. Geographical Analysis, 45(1), $49-76$.

Morrissey, K, O'Donoghue, C, and Farrell, N. (2014). The Local Impact of the Marine Sector in Ireland: A Spatial Microsimulation Analysis. Spatial Economic Analysis, 9(1), 31-50. 
Nagel, K. and Wagner, P. (2002). Editorial special issue "Regional Transportation Simulations", Networks and Spatial Economics, 2: 325-326.

Nakaya, T., Fotheringham, A.S., Hanaoka, K., Clarke, G.P., Ballas, D. and Yano, K., (2007). Combining microsimulation and spatial interaction models for retail location analysis, Journal of Geographical Systems, 4, 345-369.

Nielsen, O.A. (2002). A Stochastic Route Choice Model for Car Travellers in the Copenhagen Region. Networks and Spatial Economics, 2: 327.346.

Nguyen-Luong, D. and Moran, M.S. (2008). An integrated land use-transport model for the Paris region (SIMAURIF): Ten lessons learned after four years of development. Transportation Research Board Annual Meeting 2009 Paper \#09-0024.

Norman, P., (1999). Putting Iterative Proportional Fitting on the Researcher's Desk School of Geography University of Leeds, Working Paper 99/03.

O’Donoghue C. (2001), "Dynamic Microsimulation: A Survey", Brazilian Electronic Journal of Economics.

O’Donoghue, C., Lennon, J., Loughrey. J. and Meredith, D. (2012). Short and Medium-Term Projections of Household Income in Ireland using a Spatial Microsimulation Model. Teagasc Rural Economy and Development Programme Mimeo.

O’Donoghue, C., Hynes, S., Morrissey, K., Ballas, D. and Clarke, G. (Eds.), (2013a), Spatial Microsimulation for Rural Policy Analysis. Springer-Verlag.

O’Donoghue, C., Dillon, E., Green, S., Hennessy, T., Hynes, S., and Morrissey, K., (2013b). Assessing the Sustainability of Irish Farming Across Space in O’Donoghue C., S. Hynes, K. Morrissey, D. Ballas and G. Clarke, Modelling the Local Economy: A Simulation Approach. Springer Verlag.

Oskamp, A., (1997). Local housing market simulation: A micro approach. Amsterdam, Thesis Publishers, 204 pp.

Peters, I., Brassel, K.H., and Spörria, C., (2002) A Microsimulation Model for Assessing Urine Flows in Urban Wastewater Management, iEMSs 2002 sessions (part two) Techniques and Methodologies. 
Pesti, C.S. and Kaposzta, J., (2008). Adaptation of Statistical Matching in Micro-Regional Analysis of Agricultural Production. Bulletin of the Szent Istvan University, Godollo.

Pendyala, R.M., Kitamura, R. and Prasuna Reddy, D.V.G. (1995) A rule-based activity-travel scheduling algorithm integrating neural networks of behavioral adaptation. Paper presented at the Conference on Activity Based Approaches: Activity Scheduling and the Analysis of Activity Patterns, Eindhoven, May.

Pendyala, R.M., Kitamura, R. Chen, C. and Pas, E.I. (1997). An activity-based microsimulation analysis of transportation control measures. Transport Policy, Vol. 4, No. 3, pp. 183-192.

Phillips, B. and Kelly, S., (2006). Housemod: A Regional Microsimulation Projections Model of Housing in Australia. Paper Presented to Australian Housing Research Conference Paper 19 21 June.

Phillips, B, Chin, SF and Harding, A, (2006). 'Housing Stress Today: Estimates for Statistical Local Areas in 2005', Paper given at Australian Consortium for Social and Political Research Incorporated Conference, Sydney, 10-13 December 2006.

Potter, S., Atwood, J., Lemunyon, J. and Kellogg, R. (2009). A National Assessment of Soil Carbon Sequestration on Cropland: A Microsimulation Modeling Approach. Soil Carbon Sequestration and the Greenhouse Effect, 2nd edition. SSSA Special Publication 57.

Pritchard, D.R. and Miller, E.J. (2008). Development of an Operational Integrated Urban Model System Volume III - Synthesizing Base Year Agents. Toronto: Urban Transportation Research and Advancement Centre.

Raney, B., Cetin, N., Voellmy, A., Vrtic, M. Axhausen, K. and Nagel, K., (2003) An Agent-Based Microsimulation Model of Swiss Travel: First Results. Networks and Spatial Economics, 3: (2003) 23.41 .

RDC, Inc. (1995) Activity-Based Modeling System for Travel Demand Forecasting. A Travel Model Improvement Program (TMIP) final report prepared for Metropolitan Washington Council of Governments, Washington, D.C. San Francisco, California, August.

Rephann, T.J., (2001). Economic-demographic effects of immigration: Results from a dynamic, spatial microsimulation model. Paper to be presented at the 2001 Annual Meeting of the MidAtlantic Division of the Association of American Geographers on October 5, in Frostburg, 
Maryland.

Rephann, T. J. and Öhman, M., (1999). Building a Microsimulation Model for Crime in Sweden: Issues and Applications. Paper to be presented at the eminarium om Ekobrottsforskning in Stockholm, Sweden February 22.

Rephann, T.J., (2002), The importance of geographical attributes in the decision to attend college. Socio-Economic Planning Sciences Vol. 36 No. 291-307.

Rephann, T.J., Makila, K. and Holm, E., (2005). Microsimulation for Local Impact Analysis: An Application to Plant Shutdown. Journal of Regional Science, Vol. 45, No. 1, pp. 183-222.

Santos, G. and Rojey, L., (2004). Distributional impacts of road pricing: The truth behind the myth. Transportation. 31(1), pp. 21-42.

Simpson, L. and Tranmer, M. (2005). Combining sample and census data in small area estimates: Iterative proportional fitting with standard software. Professional Geographer, 57, 222-234.

Sivakumar, A., (2007). Modelling Transport: A Synthesis of Transport Modelling Methodologies. Mimeo Imperial College (http://www3.imperial.ac.uk/pls/portallive/docs/1/50669701.PDF) last accessed December 30th, 2009.

Smith, D.M., Harland, K. and Clarke, G.P., (2007). SimHealth: estimating small area populations using deterministic spatial microsimulation in Leeds and Bradford. University of Leeds School of Geography, Working Paper 07/06.

Smith, D. M., Clarke G. P. and Harland K., (2009), "Improving the synthetic data generation process in spatial microsimulation models" Environment and Planning, 41(5) 1251 - 1268.

Spiekermann, K., and Wegener, M. (1996). Trans-European networks and unequal accessibility in Europe. European Journal of Regional Development, 4, 35-42.

Spielauer (2011). What is Social Science Microsimulation?, Social Science Computer Review, 29(1), 920.

Strauch, D., Moeckel, R., Wegener, M., Gräfe, J., Mühlhans, H., Rindsfüser, G. and Beckmann, K.J., (2005). Linking Transport and Land Use Planning: The Microscopic Dynamic Simulation Model ILUMASS. In Atkinson, P. M., Foody, G. M., Darby, S. E., Wu, F. (Eds): Geodynamics. Boca Raton, Florida: CRC Press, 2005, 295-311. 
Svoray, T. and Benenson, I., (2009). Scale and adequacy of environmental microsimulation, Ecological Complexity Vol. 6 pp.77-79.

Tanton, R., \& Edwards, K. L. (2013). Introduction to Spatial Microsimulation: History, Methods and Applications. In Spatial Microsimulation: A Reference Guide for Users (pp. 3-8). Springer Netherlands.

Tanton, R. (2009). Spatial Microsimulation as a Method for Estimating Different Poverty Rates in Australia. Population, Space and Place Vol. 10.

Tanton, R., Vidyattama, Y., Nepal, B. and McNamara,J. (2011), Small Area Estimation Using A Reweighting Algorithm . Journal of the Royal Statistical Society: Series A (Statistics in Society), 174, 4, 931-951.

Tanton, R., McNamara, J., Harding, A. and Morrison, T. (2009), 'Rich suburbs, poor suburbs? Small area poverty estimates for Australia's eastern seaboard in 2006'. In A Zaidi, A Harding and P Williamson, New Frontiers in Microsimulation Modelling, Ashgate, London.

Tanton, R. (2014), 'A Review of Spatial Microsimulation Methods', International Journal of Microsimulation 7(1), 4-25.

Tanton, R. and Williamson, P. (2014), 'Comparing Two Methods of Reweighting a Survey File to Small Area Data', International Journal of Microsimulation, 7(1), 76-99.

Tiglao, N.C., (2002), Small Area Estimation and Spatial Microsimulation of Household Characteristics in Developing Countries with a Focus on Informal Settlements in Metro Manila., unpublished PbD thesis, University of Tokyo.

Van Imhoff, E., and Post W., (1998). Microsimulation methods for population projection. Population, 10(1) p. $97-136$.

Van Imhoff, E. and Keilman, N. (1991). LIPRO 2.0: An Application of a Dynamic Demographic Projection Model to Household Structure in the Netherlands. NIDI/CBGS Pubications nr. 23, Amsterdam/Lisse: Swets \& Zeitlinger.

Van Laarhoven, P. J., and Aarts, E. H. (1987). Simulated annealing (pp. 7-15). Springer Netherlands.

Van Leeuwen, E., Dekkers, J. and Rietveld, P., (2008). The Development of a Static Farm-Level Spatial Microsimulation Model to Analyse on and off farm activities of Dutch Farmers 
Presenting the research framework. Paper presented to the 3rd Israeli - Dutch Regional Science Workshop.

Van Leeuwen, E. S., Clarke, G.P. and Rietveld, P., (2009). "Microsimulation as a Tool in Spatial Decision Making: Simulation of Retail Developments in a Dutch Town”, in P. Williamson, A. Zaidi and A. Harding (eds) New Frontiers in Microsimulation Modelling. Ashgate.

Van Leeuwen, E. and Nijkamp, P., (2009). A Micro-simulation Model for E-Services in Cultural Heritage Tourism. VU University Mimeo, Amsterdam.

Van Soest, A., (1995). Structural models of family labor supply: a discrete choice approach, Journal of Human Resources, Vol. 30. No. 1, pp 63-88.

Van Wissen, L., (2000). A micro-simulation model of firms: Applications of concepts of the demography of the firm. Papers in Regional Science. Vol. 79, pp 111.

Veldhuisen, J., Timmermans, H., Kapoen, L., (2000a). RAMBLAS: a regional planning model based on the microsimulation of daily activity travel patterns, Environment and Planning A 32(3) $427-443$.

Veldhuisen, J., Timmermans, H., Kapoen, L., (2000b). Microsimulation Model of Activity-Travel Patterns and Traffic Flows: Specification, Validation Tests, and Monte Carlo Error, Transportation Research Record: Journal of the Transportation Research Board. Volume 1706, 126-135.

Veldhuisen, J., Timmermans, H., Kapoen, L. (2005), "Simulating the effects of urban development on activity - travel patterns: an application of Ramblas to the Randstad North Wing" Environment and Planning B: Planning and Design 32(4) 567 - 580.

Vencatasawmy, C.P., Holm, E., Rephann, T., Esko, J., Swan, N, Öhman, M., Åström, M., Alfredsson, E., Holme, K., and Siikavaara, J., (1999). Building a spatial microsimulation model. Paper to be presented at the 11th European Colloquium on Quantitative and Theoretical Geography in Durham, England, on September 3-7.

Vidyattama, Y and Tanton, R (2013). "Projections Using a Static Spatial Microsimulation Model." In Tanton and Edwards (eds), Spatial Microsimulation: A Reference Guide for Users, pp. 145 - 160, Springer.

Vidyattama, Y, Rao, M, Mohanty, I and Tanton, R (2014), 'Modelling the impact of declining 
Australian terms of trade on the spatial distribution of income', International Journal of Microsimulation 7(1), 100-126.

Voas, D., \& Williamson, P. (2000). An evaluation of the combinatorial optimisation approach to the creation of synthetic microdata. International Journal of Population Geography, 6, 348-366.

Wachter, K. W., Blackwell, D., \& Hammel, E. A. (1997). Testing the validity of kinship microsimulation. Mathematical and Computer Modelling, 26(6), 89-104.

Waddell, P. (2000a), Monitoring and Simulating Land Capacity at the Parcel Level, in VernezMoudon, A. and Hubner M., (eds.), Monitoring Land Supply with Geographic Information Systems: Theory, Practice and Parcel-Based Approaches. New York: John Wiley \& Sons, Inc.

Waddell, P. (2000b), A behavioural simulation model for metropolitan policy analysis and planning: residential location and housing market components of Urban Sim, In Environment and Planning B: Planning and Design, Volume 27, 247-263.

Waddell, P. (2002). UrbanSim: Modeling Urban Development for Land Use, Transportation and Environmental Planning. Journal of the American Planning Association, Vol. 68 No. 3, Summer, pages 297-314.

Waddell, P. and Borning, A., (2004) A Case Study in Digital Government: Developing and Applying UrbanSim, a System for Simulating Urban Land Use, Transportation, and Environmental Impacts, Social Science Computer Review, Vol. 22 No. 1, February, pages 37-51.

Waddell, P. and Ulfarsson, G.F., (2004) Introduction to Urban Simulation: Design and Development of Operational Models. In, Stopher, Button, Kingsley, Hensher eds. Handbook in Transport, Volume 5: Transport Geography and Spatial Systems Pergamon Press, pages 203-236.

Wegener, M., (2004). Overview of Land-Use Transport Models, in David A Hensher, Kenneth J Button, Kingsley E Haynes, and Peter Stopher (eds.) Handbook of transport geography and spatial systems, Volume 5. Kidlington: Pergamon/Elsevier Science.

Wegener, M., and Spiekermann, K. (1996): The potential of microsimulation for urban models. In: Clarke, G. (Ed.): Microsimulation for Urban and Regional Policy Analysis. European Research in Regional Science 6. London: Pion, 146-163.

Weidner, Donnelly, Freedman, Abraham, and Hunt Page, (2007). A summary of the Oregon 
TLUMIP Model Microsimulation Modules. Paper presented to Transportation Research Board.

Wilson, A. G., \& Pownall, C. E. (1976). A new representation of the urban system for modelling and for the study of micro-level interdependence. Area, 8, 256-264.

Wilson, A.G., (1998). Land-use/transport interaction models: Past and future. Journal of Transport Economics and Policy, Vol 32, no. 1, 3-26.

Williamson, P. (1992) Community health care policies for the elderly: a microsimulation approach, Unpublished Ph.D. Thesis, School of Geography, University of Leeds.

Williamson, P. (1996) Community care policies for the elderly, 1981 and 1991; a microsimulation approach, in G Clarke (ed) Microsimulation for urban and regional policy analysis, Pion, London, 64-87.

Williamson, P. (2009). Creating synthetic sub-regional baseline populations. ESRC microsimulation series, London, 9.

Winder, N. (2000). Modelling within a thermodynamic framework : a footnote to Sanders (1999). Cybergeo : European Journal of Geography. Systèmes, Modélisation, Géostatistiques, article 138. consulté le 09 juin 2012. URL : http://cybergeo.revues.org/2289 ; DOI : $10.4000 /$ cybergeo.2289.

Wu, B., Birkin, M., Rees, P. (2008). A spatial microsimulation model with student agents, Computers Environment and Urban Systems, 32, 440-453.

Wu, B., (2009). Dynamic micro-simulation with spatial interactions. ESRC Microsimulation Seminar Series: 'Scaling up; scaling down', London, 2nd April.

Xu, M., Taylor, M. and Hamnett, S., (2003). A microsimulation model of travel behaviour for use in urban transport corridor analysis. Paper Presented Session IV, Moving through nets: The physical and social dimensions of travel, 10th International Conference on Travel Behaviour Research, Lucerne, 10-15 August.

Zhao, F. and Chung, S. (2006). A study of alternative land use forecasting models - final report, Technical Report BD015-10, Florida Department of Transportation, Tallahassee, Florida.

Zhou, B. and Kockelman, K.M., (2010). Land Use Change through Microsimulation of Market 
Dynamics: An Agent-based Model of Land Development and Locator Bidding in Austin, Texas. Submitted for presentation to the 89th Annual Meeting of the Transportation Research Board, 26 January 2010 in Washington, DC.

${ }^{1}$ See for example http://webscripts.softpedia.com/script/Miscellaneous/General-simulated-annealing-algorithm34475.html.

2 Most of the validation in this paper focuses on inter-temporal validation as a major component of the model is inter-temporal. Base data production is less onerous being able to use spatial micro data.

3 Used for example in Holm et al., (2002) to dynamic age the Swedish population. 